\title{
VIII. DJV und MdJ in der Justizsteuerung (1949-1951)
}

\section{Voraussetzungen und Anfänge (1949/50)}

Im Gegensatz zum Obersten Gericht und zur Obersten Staatsanwaltschaft, die sich erst in den Jahren zwischen 1949 und 1952 als justizsteuernde Instanzen etablieren konnten, besaß die DJV 1949 weitaus bessere Voraussetzungen, um die Rechtsprechung von Berlin aus lenken zu können. Denn ihr wurde im Zuge der Gleichschaltung der Landesjustizverwaltungen der Zugang zu den Gerichten und Staatsanwaltschaften erheblich erleichtert, und zudem waren diese schon seit 1945 an Anweisungen aus der Zentralverwaltung gewöhnt. Die Rundverfügungen der DJV hatten indes die richterliche Unabhängigkeit nur dann beeinträchtigt, wenn dies - wie im Zusammenhang mit Befehl Nr. 160 - von der SMAD verlangt worden war. Damalige Versuche, mittels eines rudimentären Berichtswesens und vereinzelter Revisionen sowie mündlicher oder schriftlicher Anweisungen die Rechtsprechung von der DJV aus zu steuern, waren weitgehend erfolglos geblieben. Eine Systematisierung erfuhr die justizsteuernde Tätigkeit der DJV erst nach deren Reorganisation zum 1. Januar 1949, die die Erstellung von Halbjahresplänen der einzelnen Abteilungen nach sich zog.

Die Kontrollabteilung entwarf ihren Arbeitsplan unter Rückgriff auf eine Entschließung der Justizkonferenz vom November 1948, die Kontrolltätigkeit der Justizverwaltung vor allem im Hinblick auf die Wirtschaftsstrafverfahren „schnellstens“ zu erweitern und zu systematisieren". Dazu sollten vor allem die Kontrollabteilungen der Landesjustizministerien überprüft, eine Reihe von $\mathrm{Ge}$ richten insbesondere auf Wirtschaftsstrafsachen hin revidiert und den Justizbehörden „allgemeine Hinweise" zur Verbesserung der diesbezüglichen Rechtsprechung gegeben werden². Der Plan wurde von der SMAD-Rechtsabteilung gebilligt; gleichzeitig gab Nikolajew drei grundsätzliche „Hinweise“, die der DJV die Richtung der Kontrolle - und damit implizit auch der Anleitung - vorgaben. Erstens war „die Gerichtspraxis (Rechtsprechung) auf bestimmten Gebieten zusammenzufassen": Konkret benannt wurden die Behandlung des Volkseigentums in der Zivilrechtsprechung und in der Strafrechtsprechung der Widerstand gegen die Staatsgewalt sowie Verstöße gegen die Wirtschaftsstrafverordnung. Zweitens sollte die Kontrollabteilung sich nicht in Einzelfragen verlieren, „sondern sich auf grundsätzliche Gesichtspunkte konzentrieren“ und vor allem einzelne Gruppen

1 Die zweite Juristenkonferenz, S. 267. Die Resolution ist indirekt auf den Prozeß von GlauchauMeerane zurückzuführen. Siehe dazu Abschnitt 4 dieses Kapitels.

2 Arbeitsplan der Abteilung II/3, gez. Heinze, BAB, DP1 VA Nr. 6214. 
von Verbrechen - „Sabotage, Brandstiftung, Widerstand gegen die Staatsgewalt“ analysieren, „wobei vor allen Dingen eine klassenmäßige Betrachtung erfolgen muß“. „Diese Analyse muß dazu führen“, so Nikolajew weiter, „daß man bestimmte typische Gründe ermittelt, die zur Begehung von Verbrechen geführt haben, mit dem Ziel, die Verbrechen zu verhüten und rechtzeitig zu verhindern.“ Drittens habe die Abteilung II/3 - im Unterschied zur bisherigen Praxis - die Aktivitäten der Kontrollabteilungen in den Landesjustizministerien zur Abstellung von bei Gerichtsrevisionen festgestellten Mängeln zu überwachen ${ }^{3}$. Neben einer Intensivierung der Justizsteuerung zielte die Unterredung also auch auf die Übernahme der sowjetischen Vorstellung, daß Verbrechen vor allem klassenbedingt seien. Eine ähnliche Richtung gab eine von Nikolajew am 19. Mai 1949 übergebene „Disposition für einen Halbjahresbericht“ vor. Unter der Rubrik „Arbeit der Gerichte“ war auch deren "Kampf gegen besonders gefährliche Verbrechen“ darzustellen und zu analysieren. Die ,Anregungen" wurden bereits mit dem $\mathrm{Ar}$ beitsplan der Abteilung II/3 für das zweite Halbjahr 1949 umgesetzt, der - bereits im typischen DDR-Jargon - auf „eine weitere Verstärkung der Kontrolle der Rechtsprechung insbesondere in Wirtschaftsstrafsachen einschließlich Unfallstraf- und Brandsachen" abzieltes.

Da die DJV nicht über einen, direkten Draht' zu den Staatsanwaltschaften und Gerichten verfügte, war eine systematische Anleitung der Rechtsprechung nur über die Landesjustizministerien möglich. Die Vereinheitlichung der Justizressorts bezweckte unter anderem eine Verstärkung der Kontrollabteilungen, „um eine wirksame Kontrolle der Rechtspflege durchzuführen“. Eine Vereinheitlichung war nach Ansicht der DJV auch innerhalb der Kontrollabteilungen nötig, so daß sie die Justizministerien anwies, diese nach dem Muster der Berliner Zentralverwaltung aufzubauen ${ }^{6}$. Die Organisationsangleichung sollte die Kommunikation hinsichtlich der Kontrolle und der Anleitung der Rechtsprechung für die Zentrale erleichtern; die DJV strebte nun auch eine Parallelisierung der Arbeitsweise von Zentralverwaltung und Landesministerien an. Am sinnfälligsten kommt dies in der Anweisung an die Landesjustizressorts zum Ausdruck, eine Liste mit den wichtigsten Wirtschaftsstrafsachen in jeder Kontrollabteilung anzulegen, „aus der jederzeit der Stand des Verfahrens ersichtlich ist“; auch die Kontrollabteilung der DJV wollte eine entsprechende Liste erstellen, die durch Mitteilungen aus den Ländern jeweils auf den neuesten Stand zu bringen war?

3 Heinze an Referenten der Abt. II/3, 2. 3. 1949, BAB, DP1 VA Nr. 575, Bl. 1.

4 Vermerk Heinzes, 19. 5. 1949, mit Anlage, BAB, DP1 VA Nr. 5572. Unter der Überschrift „Kampf gegen besonders gefährliche Verbrechen" führte die Disposition auf: Befehl 201 und [Kontrollrats]Gesetz 10, Befehl 160, Wirtschaftsstrafverordnung, Diebstahl von Volkseigentum und Angriffe auf volkseigene Betriebe, Befehl 161, Spekulationsverbrechen und Angriffe gegen Vertreter „demokratischer Einrichtungen".

5 Arbeitsplan der Abteilung II/3 für das 2. Halbjahr 1949, 12. 8. 1949, BAB, DP1 VA Nr. 656, Bl. 20.

6 Chef der DJV an Landesregierungen/Justizministerium, 31. 12. 1948, BAB, DP1 VA Nr. 6403. Die Gliederung der Kontrollabteilung umfaßte: I. Statistik, Berichterstattung, Gerichtsorganisation; II. Kontrolle: 1. Kontrollangelegenheiten im allgemeinen, 2. Zivilsachen und öffentliches Recht, Revisionen der Justizbehörden, 3. Strafsachen und Revisionen der Justizbehörden, 4. Wirtschaftsstrafsachen und Revisionen der Justizbehörden.

7 DJV an Landesregierungen/Justizministerium, 24. 8. 1949, BAB, DP1 VA Nr. 7582. 
Um zu überprüfen, ob die Kontrollabteilungen auch die Weisungen der DJV einhielten, führte Heinze Anfang Juni 1949 Revisionen in Sachsen und SachsenAnhalt durch - beides Justizministerien, bei denen die DJV im Frühjahr 1948 bzw. Anfang 1949 erhebliche Mängel festgestellt hatte ${ }^{8}$. Dabei hatte es jedoch anscheinend sein Bewenden, so daß die Justizressorts in den anderen Ländern wohl unüberprüft blieben: ein Hinweis darauf, daß der Wille und die Fähigkeit zu einer allgemeinen Kontrolle sich nicht deckten. Einer intensiveren Anleitung diente auch die Abstimmung der Arbeitspläne zwischen der Zentrale und den Kontrollabteilungen der Landesministerien, die am 6. Dezember vorgenommen wurde9. Derartige Treffen in Berlin fanden jedoch noch recht selten statt, und deren Frequenz konnte im Verlauf des Jahres 1950 kaum gesteigert werden ${ }^{10}$.

Zur Kontrolle der Rechtsprechung waren DJV und MdJ auf ein funktionierendes Berichtswesen angewiesen. Die DJV hatte seit 1946 aufgrund von sowjetischen Anweisungen in einer ganzen Reihe von Strafsachen die Übersendung von Abschriften aller Anklagen und Gerichtsurteile verlangt und damit die Fundamente für die spätere Berichterstattung der Landesjustizministerien gelegt. Im Herbst 1948 kam die Abteilung Rechtsprechung der DJV zu dem Schluß, daß das Berichtswesen völlig neu organisiert werden müsse. Denn einerseits wurde sie wie beim „Fall Glauchau-Meerane“ 11 - „immer noch unvollständig und in fast allen wirklich wichtigen Fällen entweder überhaupt nicht oder zu spät informiert $^{\text {" }}{ }^{12}$. Andererseits konnte die Kontrollabteilung angesichts der umfassenden Berichtsaufträge, etwa in Verfahren nach Kontrollratsgesetz $\mathrm{Nr} .50$ und den SMAD-Befehlen Nr. 160 und 201, kaum die Übersicht behalten. Daher wurde zum 22. November 1948 eine grundsätzliche Neuordnung der Berichtspflichten angeordnet. Nun waren nur noch in wichtigen Strafsachen Abschriften der Urteile und Anklagen bei der DJV einzureichen. Neben eher unbestimmten Kriterien für die Wichtigkeit („Schädigung der Interessen des Volkes“, besonderes Interesse der Bevölkerung, grundlegende Bedeutung „in tatsächlicher und rechtlicher Hinsicht") nannte die Rundverfügung folgende Fälle, in denen immer zu berichten war: „1. Sachen, in denen die Todesstrafe verhängt wird, 2. Wirtschaftsverbrechen, die durch die Landeskontrollkommissionen oder Zentrale Kontrollkommission eingeleitet wurden [sic], 3. alle Verfahren gemäß Direktive 38 III A III, 4. Strafverfahren, die auf Veranlassung der Besatzungsmacht eingeleitet werden, 5. Angriffe gegen die Besatzungsmacht und SAG's und schwere Angriffe gegen das Volkseigentum“. Darüber hatten die Oberstaatsanwälte bei den Landgerichten die DJV direkt zu informieren; die Berichtspflichten der Justizministerien wurden hingegen verringert ${ }^{13}$. Trotz ihrer herausragenden Bedeutung für die Justizsteuerung blieb die Art und Weise der Berichterstattung für DJV und MdJ

8 Protokoll über die Referentenbesprechung der Abt. II/3, 11.6. 1949, BAB, DP1 VA Nr. 6968.

9 Protokoll der Arbeitsbesprechung im MdJ am 6. 12. 1949, BAB, DP1 VA Nr. 656, Bl. 29-31.

10 Solche Arbeitsbesprechungen fanden im MdJ nachweislich am 21. 10. 1949, 28. 3. 1950 und 24.8. 1950 statt: BAB, DP1 VA Nr. 17, Bl. 56-59; Reuter, Brandstifter; Vermerk Ganske, 28. 8. 1950, BAB, DP1 VA Nr. 332, Bl. 12.

11 Siehe dazu Abschnitt 4 dieses Kapitels.

12 So Hermann Hirschfeld in einem Vermerk vom 25. 10. 1948, BAB, DP1 VA Nr. 516, Bl. 6.

13 Chef der DJV an Landesregierungen/Justizministerium, 22.11. 1948, BAB, DP1 VA Nr. 516, Bl. $13 \mathrm{f}$. 
stets unbefriedigend; dazu trugen wahrscheinlich auch die zahlreichen inhaltlichen Änderungen und Ergänzungen der Berichtspflichten bei ${ }^{14}$, bis diese ab dem 23. Oktober 1950 wieder eine grundsätzliche Neuregelung erfuhren, mit der man neuen Strafnormen bzw. neu festgelegten "Schwerpunkten“ der Strafrechtsprechung Rechnung trug ${ }^{15}$. Insgesamt läßt sich daher auch an den Festlegungen für die Berichterstattung ablesen, welche politischen und Wirtschaftsstrafsachen im Zentrum des allgemeinen Interesses und damit der Bemühungen um Justizsteuerung standen.

Die einzige Möglichkeit, die Rechtsprechung der Gerichte genau zu überprüfen, bildeten Revisionen der Landesjustizministerien und der Berliner Zentrale. Dabei unterlagen die Revisionen der Landesjustizministerien ab 1949 in verstärktem Maße der Kontrolle und Anleitung durch DJV und MdJ, was sich in einer vermehrten Kritik an deren Quantität und Qualität äußerte: Im ersten Halbjahr 1950 etwa seien diese „zu schematisch“ und nur formal durchgeführt worden, ohne sich „auf das Wesentliche [zu] konzentrieren und insbesondere die Schnelligkeit und Güte der Rechtsprechung " zu beachten ${ }^{16}$. Die DJV selbst hatte seit 1946 Gerichte und Staatsanwaltschaften revidiert und, sofern es sich um Gesamtrevisionen handelte, versucht, zu einer möglichst umfassenden Beurteilung der jeweiligen Behörde zu gelangen. Die Revisionsberichte enthalten daher Aussagen unter anderem zur Unterbringung, zur Besetzung, zum Arbeitsanfall und zur Rechtsprechung, wobei letztere jedoch nur bei eindeutigen Verstößen gegen Gesetze und Verfahrensbestimmungen kritisiert wurde. Eine erste Abweichung von dieser Linie bildete ein Revisionsbericht vom 19. Januar 1949 über die Landgerichte Weimar und Eisenach und die Staatsanwaltschaft Jena, in dem Julie Ganske immer wieder die zu milden Urteile bemängelte ${ }^{17}$. Die „Güte der Rechtsprechung" wurde somit ab Anfang 1949 nicht nur an der Einhaltung von Gesetzen und Verordnungen, sondern auch an der Höhe des Strafmaßes festgemacht. Zudem erhielten die Referenten der Kontrollabteilung eine von Heinze verfaßte „Übersicht über die Revisionen von Gerichten in der Sowjetunion“ mit der Maßgabe, diese Zusammenstellung „bei der zu erlassenden ,Rundverfügung über Richtlinien zur Durchführung von Revisionen' zu berücksichtigen"18 - ein weiterer Hinweis auf die geplante Ausrichtung der Revisionen in der DDR. Inwieweit die seit 1949 geplante Ausweitung der Revisionstätigkeit der Abteilung II/319 rea-

14 Siehe u.a. die Rundverfügungen vom 2. 4., 16. 6., 22. 12. 1949, ebenda, Bl. 28, 32, $40 \mathrm{f}$.

15 Rundverfügung Nr. 137/50, 23. 10.1950, ebenda, Bl. 58-62. Damit wurden frühere Einzelregelungen zusammengefaßt; angefordert wurden Berichte zu: Strafverfahren, in denen ein Todesurteil ergangen, aber noch nicht vollstreckt war, Strafverfahren aufgrund von Artikel 6 der DDR-Verfassung und Artikel III A III von KRD 38, Strafverfahren aufgrund von Finanzverbrechen, Strafverfahren aufgrund des Handelsschutzgesetzes, Strafverfahren wegen Sabotage- und Agententätigkeit und aus anderen wirtschaftspolitischen Gründen, Strafverfahren wegen Brandstrafsachen.

16 Bericht über die Tätigkeit des Ministeriums der Justiz und der Ministerien der Länder im 1. Halbjahr 1950, BAB, DP1 SE Nr. 3361.

17 Revisionsbericht betr. die Landgerichte Weimar und Eisenach und die Staatsanwaltschaft Jena (6.11. 12. 1948), BAB, DP1 SE Nr. 624, Bl. 153-171, hier Bl. 158ff., 164. In dieser Akte auch andere Revisionsberichte der DJV aus den Jahren 1946 bis 1949.

18 Protokoll über die Referentenbesprechung der Hauptabteilung II vom 13. 4. 1950, BAB, DP1 VA Nr. 652.

19 Siehe den Arbeitsplan der Abteilung II/3 vom Januar 1949, BAB, DP1 VA Nr. 6214, und den Arbeitsplan der Abteilung II/3 für das 2. Halbjahr 1949, 12. 8. 1949, BAB, DP1 VA Nr. 656, Bl. 20. 
lisiert wurde, läßt sich nur punktuell feststellen. So führte die Hauptabteilung Rechtsprechung im ersten Halbjahr 1950 lediglich eine Gesamtrevision am großen Amtsgericht Leipzig durch ${ }^{20}$, da sie offensichtlich über zu wenig Personal verfügte, um die Justizbehörden systematisch überprüfen zu können.

Hinzu kam, daß sie zusätzlich mit einer Aufgabe belastet wurde, die nicht unmittelbar der Steuerung der Rechtsprechung diente: der Anleitung von Justizveranstaltungen. Dabei handelte es sich um öffentliche Aussprachen über aktuelle Rechtsfragen, Deliktbekämpfung und allgemeine Justizprobleme, bei denen Richter und Staatsanwälte gegenüber der Bevölkerung Rede und Antwort standen. Als Maßnahme, die nicht nur die Justiz, sondern auch die Bevölkerung mobilisierte und die im Zusammenhang mit den Justizkonferenzen von 1948 initiiert wurde ${ }^{21}$, sollten derartige Veranstaltungen Justizfragen popularisieren, neue Gesetze und Verordnungen propagieren und damit abschreckend und vorbeugend wirken. Die Bevölkerung erhoffte sich davon insbesondere Rechtsauskünfte. Ob Justizausspracheabende darüber hinaus auch als „ein subtiles Mittel der Einflußnahme auf die Justiz" genutzt wurden, da bei diesen Gelegenheiten gezielter öffentlicher Druck auf Richter und Staatsanwälte ausgeübt werden konnte, ist angesichts der in den frühen fünfziger Jahren noch kaum von der SED gelenkten Öffentlichkeit hingegen zu bezweifeln ${ }^{22}$. Nach dem Willen der DJV sollte mit Hilfe eines Wettbewerbs die mobilisierende Wirkung solcher Veranstaltungen gesteigert werden ${ }^{23}$. Zuständig war die Kontrollabteilung, die entsprechende Berichte anforderte und registrierte24. Den aufwendigen Wettbewerb führte sie dann zwischen dem 15. November 1949 und dem 15. April 1950 durch. Eine öffentliche Preisverleihung anläßlich einer eigens dazu einberufenen Konferenz im DDR-Justizministerium am 6. Mai 1950 schloß die Aktion ab25. Fechner und Heinze sprachen von einem großen Erfolg: Insgesamt seien in diesen fünf Monaten 2011 Veranstaltungen mit über 250000 Teilnehmern durchgeführt worden. Selbst wenn diese Zahlen zutreffen sollten, so ist doch fraglich, ob die mit dem Wettbewerb verbundenen Ziele erreicht wurden. Selbst Ganske mußte zugeben, „daß die Diskussionen in vielen Fällen auch zur Rechtsberatung einzelner Zuhörer mißbraucht wurden" 26 . Bezeichnend ist jedenfalls, daß eine derartige Aktion nicht wiederholt wurde.

20 Bericht über die Tätigkeit des Ministeriums der Justiz und der Ministerien der Länder im 1. Halbjahr 1950, BAB, DP1 SE Nr. 3361; vgl. auch Bericht über das Ergebnis der Revision des Amtsgerichts Leipzig vom 5. 6. bis 10.6. 1949, BAB, DP1 VA Nr. 688. Der Halbjahresbericht des MdJ nannte zudem einige Spezialrevisionen, die vor allem Statistik, Ehe- und Grundbuchsachen sowie Handelsregistereintragungen betrafen.

21 Siehe die Entschließung der Weimarer Justizkonferenz, in: NJ 2 (1948), S. 139, und die Entschließungen der 2. Juristenkonferenz vom November 1948, ebenda, S. 266. Die Entschließungen wurden konkretisiert in: Chef der DJV an Landesregierungen/Justizministerium, 22.7. 1948, 27. 12. 1948, BAB, DP1 VA Nr. 10, Bl. 126, DP1 VA Nr. 6403.

22 So Künzel, Ministerium der Justiz, S. 175.

23 Siehe die Entschließung der 2. Justizkonferenz, in: NJ 2 (1948), S. 266, und Chef der DJV an Landesregierungen/Justizministerium, 27. 12. 1948, BAB, DP1 VA Nr. 6403.

24 Sie registrierte vom 27. 12. 1948 bis zum 10.9.1949 295 Justizveranstaltungen mit 29391 Teilnehmern: siehe die Zusammenstellung in: BAB, DP1 VA Nr. 17, Bl. 32.

25 Siehe dazu das Protokoll über die Arbeitsbesprechungen vom 21. und 27.10. 1949, sowie die Richtlinien für die Durchführung des Wettbewerbs und die Hinweise für die Durchführung von Justizveranstaltungen, 1. 11. 1949, ebenda, Bl. 56-59, 67, 69-72, 74-78. Die Referate der Justiztagung vom 6. 5. 1950 gedruckt in: Auf dem Wege zur Volksjustiz; vgl. auch Die dritte Justiztagung.

26 Auf dem Wege zur Volksjustiz, S. 14, 29, 31. 
Zwar blieben die Gerichte und Staatsanwaltschaften angehalten, alle zwei bis drei Monate Justizveranstaltungen allgemeiner Art durchzuführen ${ }^{27}$, das MdJ ging jedoch mehr und mehr dazu über, diese gezielt im Rahmen von Justizkampagnen anzuordnen ${ }^{28}$; ja, ab 1952 gab das MdJ die Themen der Justizausspracheabende alle zwei Monate zentral vor und stellte Rededispositionen zur Verfügung29. Die Veranstaltungen mögen durch ihre Informationen über drohende drakonische Strafen in Einzelfällen abschreckend gewirkt haben; die Akzeptanz der Strafjustiz in der Bevölkerung haben sie jedenfalls nicht befördert.

\section{Justizsteuerung durch das MdJ 1950-1951: Methoden, Probleme, Effektivität}

Die Arbeit der Hauptabteilung Rechtsprechung litt 1950 nicht zuletzt darunter, daß deren Leiterin durch die Waldheimer Prozesse in Anspruch genommen und anschließend zur Obersten Staatsanwaltschaft abgestellt wurde. Nach einer längeren Vakanz trat Fritz Böhme im Januar 1951 an ihre Stelle ${ }^{30}$. Hinzu kam, daß trotz bereits bestehender Überlastung der Abteilung deren Kontrolltätigkeit Fechner zufolge auf Kosten der Landesjustizministerien ausgeweitet werden sollte ${ }^{31}$. Von den für 1951 neu beantragten Stellen für die Hauptabteilung - darunter auf der gehobenen Ebene zwei Abteilungsleiter und zwei Oberreferenten ${ }^{32}$ - wurden jedoch nur wenige bewilligt, so daß zu Beginn des Jahres lediglich eine Oberreferentin und zur Jahresmitte ein weiterer Hauptreferent dort ihren Dienst aufnahmen $^{33}$.

1950/51 versuchte das MdJ die Rechtsprechung vor allem über Rundverfügungen zu steuern. Diese Kommunikationsform hatte die DJV seit 1945 im Umgang mit den Landesjustizverwaltungen erprobt; neu war die nun einsetzende massive Nutzung von Rundverfügungen zu justizsteuernden Zwecken. Diese stellten freilich nur eine indirekte Verbindung zu den Gerichten und Staatsanwaltschaften dar, da bis Ende 1951 die Landesjustizverwaltungen zwischengeschaltet waren. $\mathrm{Da}$ die MdJ-Anweisungen in den Justizministerien vervielfältigt und erst dann ihren eigentlichen Adressaten zugeschickt werden mußten, kam es dabei häufig zu Verzögerungen. Daher sah sich das Justizministerium in Berlin veranlaßt, die

27 Rundverfügung Nr. 31/50, 15. 3. 1950, BAB, DP1 VA Nr. 6283, Bl. 57 f. Daß die Justizaussprachen auf geringe Resonanz stießen, konstatiert auch Pohl, Justiz in Brandenburg (Manuskript), S. $199 \mathrm{f}$.

28 Siehe u. a. die Rundverfügungen Nr. 108/50, 21. 8. 1950, Betr:: Durchführung von Justizveranstaltungen unter dem Gesichtspunkt der Wahlvorbereitung, BAB, DP1 VA Nr. 620; Nr. 118/51, 23. 8. 1951, [über die Bestimmungen des Handelsschutzgesetzes], BAB, DP1 VA Nr. 6284, Bl. 144.

29 RVV Nr. 5/52, 24. 3. 1952, gab als Thema vor: Pflichtablieferung und Aufkauf landwirtschaftlicher Erzeugnisse im Jahr 1952, BAB, DP1 VA Nr. 619; RVV Nr. 10/52, 29. 5. 1952, gab als Thema vor: Die Bekämpfung von Brandstiftungen, BAB, DP1 VA Nr. 7586; RVV Nr. 16/52, 30. 7. 1952, gab als Thema vor: Schutz der Arbeitskraft, ebenda.

30 Siehe Kapitel B.II.3.

31 Vermerk Pätzolds für Heinze, 14. 7. 1950, BAB, DP1 VA Nr. 6966.

32 Protokoll der Abteilungsleiterbesprechung am 4. 8. 1950, ebenda; vgl. auch Protokoll über die erweiterte Referentenbesprechung der Hauptabteilung II am 24.11. 1950 unter Teilnahme Fechners, BAB, DP1 VA Nr. 6968.

33 Erna Naumann und Arthur Pannier. 
Justizressorts der Länder aus dem Übermittlungsprozeß auszuschalten: Wie von Nathan am 27. Oktober 1951 in Aussicht gestellt ${ }^{34}$, versandte das MdJ ab Dezember 1951 keine Instruktionen mehr auf dem herkömmlichen Wege, sondern nahm sie in das "Amtliche Nachrichtenblatt des Ministeriums der Justiz" auf, das am 2. Januar 1952 erstmals erschien. Durch den Druck der Rundverfügungen erfuhren diese jedoch auch eine weitere Verbreitung, so daß für vertrauliche Anweisungen die Form der „RVV“ („Rundverfügung vertraulich“) gefunden wurde, die das MdJ nicht druckte, sondern den Gerichten und Justizverwaltungen hektographiert zukommen ließ ${ }^{35}$. Im Zuge dieser Umstellung erfolgte auch eine weitere Beschneidung der Kompetenzen der Landesjustizressorts. Nach einer Anweisung vom 26. November 1951 durften Rundverfügungen "grundsätzlicher Natur“, die alle Gerichte betreffen konnten, nur noch vom MdJ in Ost-Berlin erlassen werden; falls es um eine grundsätzliche Anweisung in einer landesspezifischen Sache ging, so war diese im Entwurf dem MdJ zuzusenden, das dann entschied, ob es selbst tätig werden oder die Angelegenheit dem Land überlassen wollte; die Landesjustizverwaltungen blieben nur für Rundverfügungen zuständig, „deren Inhalt nicht grundsätzlicher Natur ist und die zweifelsfrei nur von lokaler Bedeutung sind“. Die sollten dann aber als „Rundschreiben“ bezeichnet und dem MdJ zur Information übersandt werden ${ }^{36}$. Der Versuch, die Justizsteuerung zu zentralisieren, führte somit dazu, daß die Justizressorts der Länder nur noch als ausführende Organe des DDR-Justizministeriums benötigt wurden.

Idealtypisch dienten die justizsteuernden Rundverfügungen des MdJ dazu, die bei der Kontrolle der Rechtsprechung aufgetretenen Mängel zu beseitigen. Dies war jedoch nur selten der Fall. Ein Beispiel bildet die Rundverfügung Nr. 69/50 vom 12. Juni 1950 über „Typische Mängel in Strafurteilen und Anklageschriften“, die vor allem ständig wiederkehrende formale Fehler monierte und auf die Einhaltung der Verfahrensvorschriften drängte. Die beigefügten Hinweise enthielten jedoch manches, was über die Abstellung von Formfehlern hinausging: so etwa die Anweisung, daß bei Annahme eines "minderschweren Falls" nach Wirtschaftsstrafverordnung dies von dem Gericht „im Urteil eingehend [zu] begründen“ $\operatorname{sei}^{37}$. Daß solche auf der Überprüfung der Rechtsprechung basierende Instruktionen strafverschärfend wirken konnten, zeigt beispielsweise Rundverfügung Nr. 40/51 vom 10. März 1951, die die Praxis kritisierte, bei Verurteilungen nach Kontrollratsdirektive Nr. 38, Artikel III A III, Angeklagte gemäß Artikel X der Direktive als Minderbelastete einzustufen und dann lediglich eine Bewährungsstrafe zu verhängen. Dies sei nur möglich bei den Tatbeständen, die sich auf das Verhalten der früheren Nationalsozialisten bezögen; die Vorschrift des Artikel III A III sei jedoch ein „Sondertatbestand“, bei dem eine Einstufung in die von der Direktive Nr. 38 aufgelisteten sonstigen Kategorien "nicht angebracht“ $\operatorname{sei}^{38}$.

34 Protokoll über die Arbeitstagung des MdJ am 27. 10. 1951, BAB, DP1 VA Nr. 265, Bl. 80-86, hier 86.

35 Hauptabteilung Gesetzgebung an alle Hauptabteilungen und Abteilungen, 11.12. 1951, BAB, DP1 VA Nr. 5610; ANBl. 1952, Nr. 1, S. 1.

36 Dies war bereits auf der Arbeitstagung des MdJ am 27. 10. 1951, BAB, DP1 VA Nr. 265, Bl. 86, beschlossen worden; die Rundverfügung des MdJ vom 26. 11. 1951 in: BAB, DP1 VA Nr. 5610.

37 Rundverfügung Nr. 69/50, 12. 6. 1950, BAB, DP1 VA Nr. 6283, Bl. $118 \mathrm{f}$.

38 Rundverfügung Nr. 40/51, 10. 3. 1951, BAB, DP1 VA Nr. 6284, Bl. 52. Vgl. dazu auch Analyse der 
Diese Anweisung bedeutete letztlich, daß bei politischen Straftaten Bewährungsstrafen nicht verhängt werden durften.

Die Rundverfügungen dieser Jahre verfolgten ebenfalls das Ziel, zur Selbststeuerung der Justizbehörden im Sinne einer größtmöglichen Homogenität der Rechtsprechung beizutragen. Ein Mittel dazu waren die erstmals am 20. November 1950 angeordneten, mindestens alle zwei Wochen abzuhaltenden, regelmäßigen Dienstbesprechungen. Auf diese Weise sollte die „kommunikative Einbindung " ${ }^{39}$ der Richter in ihre Gerichte gefördert und deren Rechtsprechung vereinheitlicht werden ${ }^{40}$. Eine zweite Anweisung erging in dieser Angelegenheit am 20. März 1951, da im MdJ festgestellt worden war, daß „noch immer - selbst von Richtern eines Gerichts - völlig entgegengesetzte Entscheidungen bei gleichem Sachverhalt getroffen wurden". Um dies in Zukunft zu verhindern, sollten in den Besprechungen unter anderem alle Entscheidungen des Gerichts „in formeller und materieller Hinsicht unter Berücksichtigung der Rechtsprechung des Obersten Gerichts und der Oberlandesgerichte" und laufende Verfahren von grundsätzlicher Bedeutung thematisiert werden. Letztlich untergrub eine solche „kommunikative Einbindung " die Unabhängigkeit der Richter, obwohl in der Rundverfügung explizit das Gegenteil behauptet wurde ${ }^{41}$.

In solche Besprechungen wollte Heinze auch die Staatsanwälte einbeziehen, angeblich weil „die werktätige Bevölkerung es nicht verstehe, wenn vom Richter und Staatsanwalt, die beide dazu da sind, die antifaschistisch-demokratische Ordnung zu schützen, unterschiedliche Auffassungen vertreten werden " ${ }^{42}$. Zur Beseitigung der Differenzen zwischen den Anträgen der Staatsanwälte und der Gerichtsurteile erließ das $\mathrm{MdJ}$ mehrere Anweisungen, deren erste dazu aufforderte, die Strafanträge der Staatsanwaltschaft „in jedem Fall in das Urteil aufzunehmen“. „Bei erheblichen Abweichungen des Urteils von den Anträgen der Staatsanwaltschaft", so hieß es dort weiter, „soll das Gericht sich mit den Anträgen auseinandersetzen, damit zu erkennen ist, welche Gründe zu der Abweichung geführt haben. "43 Das MdJ entnahm demzufolge nicht nur den Maßstab für die Strafzumessung prinzipiell dem Antrag des Staatsanwalts, sondern setzte auch darauf, daß die Gerichte eine aufwendige Begründung für eine mögliche Abweichung scheuen und sich an das beantragte Strafmaß halten würden. Da die beabsichtigte Wirkung jedoch nicht eintrat, erließ das Justizministerium am 10. August 1950 eine weitere Rundverfügung, in der es es offen kritisierte, „daß ein großer Teil der Richter bei der Strafzumessung von dem Grundsatz ausgeht, stets unter dem Antrag der Staatsanwaltschaft zu bleiben“. Dies sei der gegenwärtigen Entwicklung nicht mehr angemessen, da bereits der Staatsanwalt die für den Angeklagten sprechenden Umstände berücksichtige, wenngleich er „dabei stets den Interessen der

Rechtsprechung, die sich gegen die antifaschistisch-demokratische Grundordnung richtet, 9.8. 1951, BAB, DP1 VA Nr. 293, Bl. 19.

39 Der Begriff von Rottleuthner, Zur Steuerung der Justiz, S. 30.

40 Rundverfügung Nr. 148/50, 20.11. 1950, BAB, DP1 SE Nr. 1199.

41 Rundverfügung Nr. 47/51, 20.3. 1951, BAB, DP1 VA Nr.6284, Bl. 57f. Mit Rundverfügung Nr. 9/52, 20.12. 1951, in: ANBl. 1952, S. 14-16, wurde angeordnet, die Dienstbesprechungen wöchentlich abzuhalten.

42 So Heinze auf der Arbeitstagung des MdJ am 9./10. 3. 1951, in: Arbeitstagung des MdJ, S. 164.

43 Siehe Anlage A zur Rundverfügung Nr. 69/50, 12. 6. 1950, BAB, DP1 VA Nr. 6283, Bl. 119. 
Gesellschaft und des Staates den Vorrang“ gebe. Wenn auch das Gericht „den Schutz der staatlichen Interessen bei der Strafzumessung konsequent in den Vordergrund stellt, so werden diese Fälle [in denen Antrag und Urteil voneinander abweichen] nicht wie bisher die Regel darstellen" ${ }^{44}$. Mit dieser Anweisung war das in der DDR so genannte „UnA“-Verfahren („Urteil nach Antrag“) geboren, das in politischen Strafverfahren indirekt dem MfS enorme Steuerungsmöglichkeiten einräumte, da das Untersuchungsorgan mit seinem Abschlußbericht die Anklageschrift weitgehend präjudizierte ${ }^{45}$. Die Verantwortlichen im MdJ behielten dabei jedoch anscheinend ein schlechtes Gewissen: So war in der Rundverfügung eingeräumt worden, daß es „selbstverständlich immer einzelne Fälle geben [werde], in denen der Staatsanwalt es unterläßt, die zu Gunsten des Angeklagten sprechenden Tatsachen ausreichend zu berücksichtigen oder in denen die Auffassungen des Gerichts und der Staatsanwaltschaft aus anderen Gründen nicht übereinstimmen“. Jedenfalls wollte Wolfgang Weiß als Mitunterzeichner der Rundverfügung nicht den Verdacht erwecken, „es solle über die Staatsanwaltschaften, die an Weisungen gebunden sind, die Bindung der Gerichte erreicht werden " ${ }^{46}$. Im Oktober 1951 fühlte Hauptabteilungsleiter Böhme sich gar genötigt, der Ansicht entgegenzutreten, „daß das Ministerium der Justiz der DDR angeblich angeordnet habe, daß die Richter nicht von den Anträgen der Staatsanwaltschaft abweichen sollen“. "Der Richter", so fuhr er fort, „soll lediglich bei erheblichen Abweichungen von den Anträgen seine andere Ansicht in den Urteilsgründen zum Ausdruck bringen." 47 Dies entsprach der letzten aktuellen Rundverfügung zu diesem Thema, die nochmals daran erinnerte, daß die Richter bei Abweichungen vom Antrag des Staatsanwalts in ihren Urteilen dies zu begründen hätten, und bei Zuwiderhandlung mit Disziplinarmaßnahmen drohte ${ }^{48}$.

Inwieweit sich eine derartige Selbststeuerung von Gerichten und Staatsanwaltschaften durchsetzte, läßt sich nur ansatzweise bestimmen. Anfang 1951 jedenfalls stellte die sächsische Hauptabteilung Justiz fest, daß nur bei rund 50 Prozent aller Strafsachen das Strafmaß dem Strafantrag entspreche, und forderte dazu auf, nach den Gründen für die erheblichen Abweichungen zu forschen ${ }^{49}$. Eine Überprüfung der für die politischen Delikte zuständigen Abteilungen bei den Staatsanwaltschaften und Landgerichten im Februar und März 1952 ergab bereits eine weitgehende Übereinstimmung von Strafantrag und Urteil - die bei den Landgerichten Leipzig, Chemnitz und Zwickau festgestellten Abweichungen wurden teils „auf die Tendenz des sogenannten , unabhängigen Richters' [...] und teils auf die Schöffen" zurückgeführt ${ }^{50}$. Daß in politischen Strafsachen die Differenzen zwischen Anträgen und Urteilen tendenziell abnahmen, legt eine Äußerung Benjamins vom

44 Rundverfügung Nr.105/50, 10.8. 1950, BAB, DP1 VA Nr. 515, Bl. 1. Diese Rundverfügung wurde auch im Westen bekannt: siehe Unrecht als System I, S. $78 \mathrm{f}$.

45 Vgl. Werkentin, Politische Strafjustiz, S. 313-316.

46 Weiß an Heinze, 7. 8. 1950, BAB, DP1 VA Nr. 515, Bl. 2.

47 Protokoll über die Arbeitstagung am 27. 10. 1951, BAB, DP1 VA Nr. 265, Bl. 81.

48 Rundverfügung Nr. 30/51, 21. 2. 1951, BAB, DP1 VA Nr. 6284, Bl. 38.

49 Rundschreiben Nr. 5/51, 14.1. 1951, der sächsischen Hauptabteilung Justiz, in: Unrecht als System I, S. 79.

so Schlußbericht der Kommission aus Sachsen, 17. 3. 1952, BStU, MfS AS 24/55, Bl. 40 (dort das Zitat); siehe auch den Gesamtbericht über die Überprüfung der Gerichte und Staatsanwaltschaften Abt. I gemäß Politbürobeschluß vom 11. 12. 1951, 2. 4. 1952, ebenda, Bl. 211. 
August 1952 nahe, die lediglich „geringe[.] Abweichungen“ feststellte, was sie einerseits auf die „moralisch-politische Einheit zwischen Richtern und Staatsanwälten" und andererseits auf die bessere Vorbereitung der Prozesse zurückführte ${ }^{51}$. Dennoch forderte sie, auch weiterhin den Unterschieden zwischen Antrag und Urteil nachzugehen, wobei ein Abweichen nicht zu rechtfertigen sei, "wenn dies ein Zurückweichen vor der Anwendung der ganzen Härte unserer Strafgesetze bedeutet" 52 . In der politischen Strafjustiz war es nicht zuletzt wegen der zunehmenden Konformität des Rechtsstabes durchaus möglich, dieser die richterliche Unabhängigkeit elementar beschädigenden Anordnung Geltung zu verschaffen.

Sehr viel problematischer sind Aussagen über die Effektivität der zahlreichen anderen justizsteuernden Rundverfügungen, die oftmals Kampagnen im Zusammenhang mit sogenannten "Schwerpunktaufgaben" der Strafjustiz begleiteten. Bei Erlaß einer entsprechenden Anweisung ergriff das MdJ vielfach die Initiative nicht selbst, sondern war eher ausführendes Organ anderer Stellen. Dies trifft beispielsweise auf die Rundverfügungen Nr. 20/50 vom 11 . Februar und 46/50 vom 22. März $1950 \mathrm{zu}$. Die erste, die zu „Mehr Wachsamkeit in der Justiz“ aufforderte, bezog sich ausdrücklich auf die Regierungssitzungen, die der Gründung des MfS vorangegangen waren, und warnte vor Fehlern, die "Sabotagetätigkeit“ in den Justizbehörden begünstigte. Ja, sie empfahl den Richtern und Staatsanwälten ausdrücklich, „bei allen zweifelhaften Entscheidungen, die möglicherweise zu einer Beeinträchtigung des Aufbaues in der DDR führen könnten, mit den Sicherheitsund Kontrollorganen [...] vorher Fühlung aufzunehmen“53. Die zweite, zur „Verstärkung des Kampfes gegen Sabotage und Agententätigkeit" erlassene Instruktion $^{54}$ diente $z$ war formal nur der Verbreitung einer Erklärung Fechners auf einer Arbeitstagung des $\mathrm{MdJ}^{55}$, ist aber gleichwohl zumindest indirekt auf den sowjetischen Hinweis zurückzuführen, daß der Klassenkampf in der damaligen Situation durch „unsere Erfolge“ und die entsprechenden Gegenanstrengungen der Amerikaner und der „Ausbeuter" verschärft worden $\operatorname{sei}^{56}$. Auch die gemeinsam mit dem Generalstaatsanwalt im Zusammenhang mit den Wahlen vom Oktober erlassene Rundverfügung vom 14. September 1950 wurde von dem Fechner-Vertrauten Scheele „unter Verwendung von Hinweisen der Freunde“ verfaßt ${ }^{57}$ : ein weiteres Indiz dafür, daß das MdJ, wie auch bei den 1950/51 in Einzelschwerpunkten der Strafjustiz durchgeführten Kampagnen ${ }^{58}$ nur in den seltensten Fällen autonom agierte.

Von den schriftlichen Anweisungen unterschieden die Justizverwaltungen die im wesentlichen der Kontrolle dienende „operative Tätigkeit“. Die bestand ein-

51 So auch der Bericht über die Tätigkeit der Staatsanwaltschaften in der DDR im 1. Halbjahr 1952, SAPMO, DY 30 IV 2/13/408. Vgl. auch Pohl, Justiz in Brandenburg (Manuskript), S. 250.

52 Protokoll der Tagung der Bezirksstaatsanwälte und ihrer 1. Vertreter, 22. 8. 1952, BAB, DP3 Nr. 25a, Bl. 141.

53 Rundverfügung Nr. 20/50, 11. 2. 1950, BAB, DP1 VA Nr. 5576.

54 Rundverfügung Nr. 46/50, 22.3. 1950, ebenda.

55 Es handelte sich um die Arbeitstagung vom 17. 3. 1950; die Erklärung auch in: NJ 4 (1950), S. 103.

56 Besprechung Piecks mit Semjonow am 14.2. 1950, in: Badstübner/Loth, Pieck-Aufzeichnungen, S. 334.

57 Siehe Kapitel B.VII.6; Bericht Scheeles, BStU, MfS AU 307/55, Bd. 6, Bl. 172.

58 Siehe dazu weiter unten, S. 497-500. 
mal in der Teilnahme an wichtigen Gerichtsverhandlungen. In einem Bericht über die Anwendung der Wirtschaftsstrafverordnung in den ersten drei Quartalen 1951 bezeichnete das MdJ seine eigene Arbeit in dieser Hinsicht selbstkritisch als „ungenügend", verwies jedoch gleichzeitig auf verspätete Mitteilungen aus den Landesjustizverwaltungen, deren Vertreter häufiger an den Gerichtsverhandlungen teilnähmen ${ }^{59}$. Sehr viel wichtiger war die bereits 1949/50 im Mittelpunkt stehende Revisionstätigkeit, die ab 1951 verstärkt werden sollte ${ }^{60}$. Dies entsprach nicht zuletzt dem großen Interesse der SKK, die Anfang Januar 1951 über die durchgeführten Gerichtsrevisionen einschließlich der daraufhin veranlaßten Anweisungen und Maßnahmen unterrichtet werden wollte ${ }^{61}$. Ein Bericht vom April 1952 suggeriert, daß die Anzahl der von der Hauptabteilung II daraufhin durchgeführten Revisionen auf zwei pro Monat gesteigert wurde; dies erscheint eher unwahrscheinlich $^{62}$. Wie bereits 1949/50 kritisierte die Hauptabteilung Rechtsprechung zwar wiederholt die mangelnde "operative Tätigkeit" der Landesjustizressorts63, stattete diesen selbst aber kaum Kontrollbesuche $a^{64}$. Im Dezember 1950 übersandte das MdJ erstmals den Landesjustizverwaltungen detaillierte Richtlinien für die Durchführung von Revisionen ${ }^{65}$. Außerdem nutzte es eine Arbeitsbesprechung am 22. Juni 1951, um eingehend mit den Leitern der Landeskontrollabteilungen über Durchführung und Auswertung von Gerichtskontrollen sowie über die Abfassung von Revisionsberichten zu sprechen und um einen weiteren „Merkzettel“ für die Revisoren zu überreichen ${ }^{66}$. Diese Anleitungen hatten vor allem die Systematisierung und die Vereinheitlichung der Kontrolltätigkeit im Blick, wobei die Überprüfung der Rechtsprechung auf Einhaltung der zentralen Vorschriften im Vordergrund stand. Sehr viel mehr Wert als bisher legte man zudem auf die aus den Überprüfungen zu ziehenden Konsequenzen: Bei Revisionen des MdJ wurden die Ergebnisse den Hauptabteilungen Justiz mitgeteilt, die wiederum die dem Gericht aufgegebenen Maßnahmen zu kontrollieren hatten ${ }^{67}$. Daß auch dieses System nicht so funktionierte, wie es sich das $\mathrm{MdJ}$ in Berlin vorstellte, illustriert folgender Fall: Das MdJ revidierte im April 1951 die Zivilkammern des

59 MdJ an SKK-Justizabteilung, 10. 11. 1951, Betr.: Analyse der Kriminalität, der gerichtlichen Praxis und die der entsprechenden Verwaltungsorgane bei der Anwendung der Wirtschaftsstrafverordnung, BAB, DP1 VA Nr. 376, Bl. 307.

60 Siehe Schwerpunktaufgaben der Hauptabteilung II für das Jahr 1951, BAB, DP1 VA Nr.656, Bl. 87.

61 Protokoll über die Referentenbesprechung, 11.1. 1951, BAB, DP1 VA Nr. 6968.

62 So der Bericht Böhmes, 5. 4. 1952, BStU, MfS AP 11667/56, Bl. 122; angesichts der Schwierigkeiten, 1952 die Anzahl der Revisionen auf eine pro Monat zu steigern (siehe Kap. B.IX.3), muß diese Aussage jedoch bezweifelt werden.

63 Vgl. etwa MdJ an SKK-Justizabteilung, 9. 8. 1951, Betr.: Analyse der Rechtsprechung in Strafsachen, die sich gegen die antifaschistisch-demokratische Ordnung richten, BAB, DP1 VA Nr. 293, Bl. 16; MdJ an SKK-Justizabteilung, 30. 10. 1951, Betr.: Analyse der Kriminalität und der gerichtlichen Praxis in Sachen, die gegen den Befehl 160 der SMAD vom 31.12. 1945 verstoßen, BAB, DP1 VA Nr. 376, Bl. 421.

64 Bericht über die Überprüfung der Gerichte und Staatsanwaltschaften Abt. I gemäß Politbürobeschluß vom 11. 12. 1951, 2. 4. 1952, BStU, MfS AS 24/55, Bl. 212, 214; Bericht Böhmes vom 5. 4. 1952, BStU, MfS AP 11667/56, Bl. 122.

65 Rundverfügung Nr. 155/50, 11. 12. 1950, BAB, DP1 VA Nr. 6283, Bl. 238-242.

66 Niederschrift über die Arbeitsbesprechung im MdJ der DDR mit den Leitern der Abteilung Rechtsprechung der Länder am 22.6. 1951, BAB, DP1 VA Nr. 6597.

67 Vgl. MdJ an SKK-Justizabteilung, 9. 8. 1951, Betr.: Analyse der Rechtsprechung in Strafsachen, die sich gegen die antifaschistisch-demokratische Ordnung richten, BAB, DP1 VA Nr. 293, Bl. 16. 
Landgerichts Eberswalde und übersandte am 4. Mai dem Landgerichtspräsidenten einen Bericht über die Revision zu. Bei der Nachkontrolle am 4. Juli stellte die Hauptabteilung II fest, daß weder die vom Landgerichtspräsidenten eingeforderte Stellungnahme zu dem Bericht abgegangen war, noch die Richter des Landgerichts über den Revisionsbericht des MdJ in Kenntnis gesetzt, noch die Direktiven der Schlußbesprechungen - insbesondere hinsichtlich der Besetzung einiger Kammern - realisiert worden waren. Mit einer eingehenden Schilderung des Falles in einer Rundverfügung wollte das MdJ derartigen Nachlässigkeiten entgegenwir$k^{6}{ }^{68}$, obwohl dies wenig erfolgversprechend war. Jedenfalls genügte das Revisionswesen in seiner damaligen Gestalt den Verantwortlichen im MdJ ab September 1951 nicht mehr69.

Auf der Grundlage schriftlicher Berichterstattung und Revisionen erfolgte die Lenkung der Rechtsprechung auch über Zusammenkünfte mit Vertretern der Landesjustizverwaltungen im MdJ. So erklärte Böhme auf einer Arbeitstagung am 9./10. März 1951, daß „Wirtschaftsverbrechen [...] zum überwiegenden Teil als Angriffe gegen unsere antifaschistisch-demokratische Ordnung gewertet werden müssen“ und daß es eine Hauptaufgabe der Justiz sei, „die Feinde unseres Aufbaus, wie immer sie sich auch tarnen mögen, erbarmungslos zu vernichten "70. Zwei weitere Tagungen des Jahres 1951 mit den Leitern der Rechtsprechungsabteilungen der Landesjustizressorts dienten unter anderem zur Abstimmung der Arbeitspläne für das dritte und vierte Quartal71. Zur Urteilskorrektur nutzte das MdJ die Möglichkeit, eine Kassation anzuregen. Dabei einigte man sich in der Hauptabteilung II, „die Kassationsanregungen über das Landesjustizministerium dem Generalstaatsanwalt des Landes zur Weitergabe an den Generalstaatsanwalt der DDR" zuzuleiten, um auf diese Weise die Landesjustizressorts so früh wie möglich zu informieren ${ }^{72}$. Sehr viel wichtiger und effektiver waren Justizsteuerungsmaßnahmen, die dem MdJ aufgrund seiner Stellung als Dienstvorgesetzter des gesamten Justizpersonals in der DDR zustanden. Es konnte in die ,Erziehung einzelner Justizfunktionäre eingreifen und beispielsweise das Amtsgericht Bautzen anweisen, das ,in Tatbestand und Gründen völlig unzureichend[e]“ Urteil eines Richters in einer Dienstbesprechung kritisch zu behandeln, oder es bat den Landgerichtsdirektor in Potsdam, „in kollegialer Weise“ einen Amtsrichter auf gravierende Mängel in einem Urteil hinzuweisen und ihn „für die nächste Zeit durch einen Kollegen betreuen zu lassen"73. Das MdJ scheute auch nicht davor zurück, nach der Feststellung unzureichender Urteile in die Geschäftsordnung der Gerichte einzugreifen, Strafkammern umzubesetzen und Richter notfalls

68 Rundverfügung Nr. 119/51, 23. 8. 1951, BAB, DP1 VA Nr. 7311, Bl. 143-145.

69 Papier o.D. [Anfang September 1951], wohl von Böhme, BAB, DP1 VA Nr. 575, Bl. 102; vgl. Bericht Böhmes, 5. 4. 1952, BStU, MfS AP 11667/56, Bl. 119.

70 Arbeitstagung des MdJ, S. 163.

71 Niederschrift über die Arbeitsbesprechungen im MdJ der DDR mit den Leitern der Abteilung Rechtsprechung der Länder am 22. 6. und 30. 8. 1951, BAB, DP1 VA Nr. 6597; siehe auch Protokoll der Arbeitsbesprechung am 30. 8. 1951, BAB, DP1 VA Nr. 6231.

72 Protokoll über die Referentenbesprechung der Hauptabteilung II, 22. 9. 1950, BAB, DP1 VA Nr. 652.

73 MdJ an Amtsgericht Bautzen, 31. 3. 1951, BAB, DP1 SE Nr. 2740, Bl. 198; MdJ an Landgerichtspräsidenten von Potsdam, 23. 4. 1951, ebenda, ohne Paginierung. 
ihres Amtes zu entheben ${ }^{74}$. Wenn daraufhin auf ,bewährte‘ Richter zurückgegriffen wurde, konnte das Justizministerium bei späteren Kontrollen ein deutliches Absinken der etwa vorher beanstandeten Freisprüche feststellen ${ }^{75}$. Ja, im Falle des Oberrichters Hans Hoffmann vom Landgericht Rudolstadt leitete das Justizministerium nach Rücksprache mit dem DDR-Generalstaatsanwalt sogar eine gerichtliche Untersuchung ein, „die den dringenden Verdacht der vorsätzlichen Rechtsbeugung ergab". Der Oberrichter wurde daraufhin verhaftet und strafrechtlich zur Verantwortung gezogen ${ }^{76}$. Wenngleich nicht so hoch aufgehängt und spektakulär wie der Strafprozeß gegen den 1. Staatsanwalt Erhard Formann beim sächsischen Generalstaatsanwalt - bei dem Ilse Kühne und Melsheimer als Anklagevertreter fungierten und 89 Staatsanwälte und 75 Richter als Zuschauer anwesend waren ${ }^{77}$-, dürfte auch die abschreckende Wirkung des Verfahrens in Thüringen beträchtlich gewesen sein.

Neben diesen Versuchen einer allgemeinen Steuerung der Strafjustiz beteiligte sich das MdJ in den Jahren 1950/51 an mehreren gezielten Kampagnen zur Bekämpfung angeblicher Wirtschaftsverbrechen. Charakteristisch für diese Justizeinsätze war zum einen, daß die Initiativen dazu nie vom DDR-Justizministerium ausgingen, und zum anderen die massierte Anwendung aller gängigen justizlenkenden Methoden. Zunächst handelte es sich dabei um Diebstahl und Schmuggel von sogenannten Buntmetallen - also allen unedlen Metallen außer Eisen und Stahl - in den Westen. Wenn etwa Telefonkabelstücke nach West-Berlin verbracht wurden, um dort den darin enthaltenen Kupferdraht einem Altmetallhändler zu verkaufen, wurde dies zu einem Verbrechen hochstilisiert. Die polizeilichen und justitiellen Maßnahmen gegen diese im Nachkriegsdeutschland üblichen $\mathrm{Ge}-$ schäfte wurden im Herbst 1949 von der SKK in Brandenburg angeordnet ${ }^{78}$, so daß der dortige Generalstaatsanwalt Ostmann am 3. November 1949 erstmals die Staats- und Amtsanwälte anwies, Buntmetalldiebstähle „schärfstens zu verfolgen“ und die Verfahren "nicht etwa wegen Geringfügigkeit einzustellen“. Während bis Jahresende vor allem der Polizei-, Staats- und Justizapparat in Brandenburg aktiviert wurde ${ }^{79}$, schaltete sich das MdJ erstmals am 4. Januar 1950 ein, nachdem Ostmann ihm ein Exemplar seines Runderlasses vom 17. Dezember 1949 übermittelt hatte. Das MdJ gab diesen zunächst an die anderen Länder weiter und be-

74 So wurde beispielsweise nach einem nach Auffassung des MdJ ungerechtfertigten Freispruch eines Angeklagten in einer Anklage nach Artikel 6 der Vorsitzende der 1. großen Strafkammer seines Amtes enthoben; die 1. Strafkammern des Landgerichts Erfurt, die in III-A-III-Verfahren lediglich Urteile knapp über der Mindeststrafe von einem Jahr auswarfen, wurden nach einer Revision durch das MdJ umbesetzt: siehe dazu MdJ an SKK-Justizabteilung, 9. 8. 1951, Betr.: Analyse der Rechtsprechung in Strafsachen, die sich gegen die antifaschistisch-demokratische Ordnung richten, BAB, DP1 VA Nr. 293, Bl. 4, 18.

75 Dies stellte das MdJ nach den Eingriffen in Magdeburg und Erfurt fest: siehe MdJ an SKK-Justizabteilung, 10.7. 1952, Betr.: Analyse der Rechtsprechung in Strafsachen, die sich gegen die antifaschistisch-demokratische Ordnung richten, ebenda, Bl. 24.

76 MdJ an SKK-Justizabteilung, 10. 11. 1951, Betr.: Analyse der Kriminalität, der gerichtlichen Praxis und die der entsprechenden Verwaltungsorgane bei der Anwendung der Wirtschaftsstrafverordnung, BAB, DP1 VA Nr. 376, Bl. 308. Vgl. Weber, Justiz und Diktatur, S. 274.

77 Das Verfahren wurde freilich nicht vom MdJ, sondern von der Partei gelenkt: vgl. dazu Wendel, Ulbricht als Richter und Henker, S. 129-132; Werkentin, Politische Strafjustiz, S. 322.

78 Vgl. Pohl, Justiz in Brandenburg (Manuskript), S. $182 \mathrm{f}$.

79 Vgl. ebenda und Bericht betr. Buntmetalldiebstähle, 31. 1. 1950, BAB, DP1 VA Nr. 449. 
stärkte einige Tage darauf Hauptabteilungsleiter Hoeniger im Potsdamer Justizministerium darin, „mit großer Schärfe den überhandnehmenden Buntmetalldiebstählen und -schiebungen im Lande Brandenburg entgegenzutreten" 80 .

Erst am 18. Januar 1950 wandte sich das DDR-Justizministerium in einer grundlegenden Rundverfügung über die „Bekämpfung von Buntmetalldiebstählen" nicht nur an die Landesjustizministerien, sondern direkt an alle Landgerichtspräsidenten und Oberstaatsanwälte. Es forderte schnelle Verfahren und harte Bestrafungen und wies im Zusammenhang mit den anzuwenden Strafbestimmungen insbesondere auf $₫ 1$ der Wirtschaftsstrafverordnung hin. Daneben müsse in jedem Fall auch geprüft werden, „ob nicht die Tat als Sabotagehandlung nach Befehl 160 der SMAD zu werten ist auch dann, wenn eine unmittelbare Sabotageabsicht nicht nachgewiesen werden kann". Außerdem ordnete es vorbeugende Maßnahmen an und verlangte Berichte über alle seit dem 1. November 1949 ergangenen Urteile gegen Buntmetalldiebe ${ }^{81}$. Der Schwerpunkt der Aktivitäten gegen die Buntmetallaktionen lag zwar nach wie vor in Brandenburg und wurde dort von den zuständigen Instanzen gesteuert; dem MdJ fiel die Aufgabe $\mathrm{zu}$, die ursprünglich lokal begrenzte Justizkampagne auf die gesamte DDR auszuweiten. Das MdJ, auf dessen Antrag die Angelegenheit am 21. Januar auch im Ministerrat behandelt wurde ${ }^{82}$, verschaffte seinem Lenkungsanspruch propagandistisch durch eine Pressekonferenz am 19. Januar, faktisch durch Besprechungen mit den zuständigen Sachbearbeitern der Landesjustizministerien und die laufende Kontrolle der Urteile Geltung. Fielen diese zu niedrig aus, veranlaßte es entweder die Einlegung von Rechtsmitteln oder regte über den Generalstaatsanwalt des Landes Kassationen an. Darüber hinaus wurde der Generalstaatsanwalt von Mecklenburg angewiesen, „auch in personeller Hinsicht die notwendigen Konsequenzen zu treffen"; Fechner selbst ordnete die Versetzung einer Amtsrichterin aus Merseburg an, die durch ihr Versäumnis, Haftbefehl zu erlassen, die Flucht von zwei Beschuldigten ermöglicht hatte ${ }^{83}$.

Aufgrund der im Januar auch weiterhin festgestellten, aus Sicht des MdJ zu niedrigen Strafen, erließ es am 8. Februar eine weitere Rundverfügung, in der die bei den Buntmetallsachen zu beachtenden Grundsätze ergänzt und präzisiert wurden: Es sei grundsätzlich Haftbefehl zu erlassen, und die Verfahren dürften nicht eingestellt, sondern müßten beschleunigt und möglichst vor erweiterter Öffentlichkeit durchgeführt werden. Ausdrücklich hieß es darin: „Harte Strafen müssen auch bei geringen Mengen erfolgen, da durch die Häufung derartiger Diebstähle sich jede einzelne Tat schädigend auswirkt." " 84 Darüber hinaus wurden die fünf Generalstaatsanwälte telefonisch angewiesen, „, noch im Laufe des Monats März" einige spektakuläre Verfahren vor erweiterter Öffentlichkeit durchzuführen und hohe Strafen zu beantragen ${ }^{85}$. Insgesamt war die schwerpunktmäßig bis

80 Ebenda; Auszug aus dem Vermerk über die Dienstreise am 10.1. 1950 nach Potsdam (Zitat), ebenda, zit. auch bei Pohl, Justiz in Brandenburg (Manuskript), S. 183.

81 Rundverfügung Nr. 10/50, 18.1. 1950, BAB, DP1 VA Nr. 449; Hervorhebung im Original.

82 So die Darlegung in der Rundverfügung Nr. 16/50, 8. 2. 1950, ebenda.

83 Siehe das Papier „Buntmetalldiebstähle“, 2. 2. 1950, BAB, DP1 VA Nr. 7311, Bl. 398-405, hier $399 \mathrm{f}$.

84 Rundverfügung Nr. 16/50, 8. 2. 1950, BAB, DP1 VA Nr. 449.

85 Vermerk über ein Ferngespräch mit allen fünf Generalstaatsanwälten, o.D., ebenda. 
Frühjahr betriebene Aktion erfolgreich. Die von den Staatsanwaltschaften verzeichneten Neueingänge bei Buntmetallsachen gingen ab April spürbar zurück, und das verhängte Strafmaß lag weit über dem generell üblichen ${ }^{86}$. In als besonders schwer erachteten Fällen belief es sich auf neun, zehn und zwölf Jahren Zuchthaus ${ }^{87}$, so daß in der Referentenbesprechung der Hauptabteilung II zufrieden konstatiert wurde, „daß Richter und Staatsanwälte sich der Gefährlichkeit der Buntmetalldiebstähle bewußt geworden sind" 88 .

Ähnliche Aktivitäten entfaltete das Justizministerium bei der Strafverfolgung von Brandstiftungen. Obwohl die DJV bereits im Februar 1949 eine Rundverfügung in dieser Sache erlassen hatte und das MdJ im Dezember 1949 begann, eine umfassende Analyse aller Urteile in Brandsachen zu erstellen ${ }^{89}$, setzte die gezielte Justizkampagne gegen Brandstiftungen erst mit einer Regierungssitzung am 26. Januar 1950 ein. Dabei berichteten Fritz Lange (ZKK), Erich Mielke (Hauptverwaltung zum Schutz der Volkswirtschaft) und August Mayer (Deutsche Volkspolizei) über eine angeblich verstärkte Agenten-, Spionage- und Diversionstätigkeit in der DDR, um die unmittelbar bevorstehende Gründung des MfS zu legitimieren ${ }^{90}$. Der daraufhin gefaßte Regierungsbeschluß „über die Abwehr von Sabotageakten“ stellte dann auch fest, daß „der Feind“ zur Zeit alles daran setze, „um durch Sabotage, Brandstiftung usw. die Durchführung des Wirtschaftsplanes und der sonstigen Maßnahmen zu stören“. Und weiter hieß es darin: „Organisierte Brandstiftungen, die im erschreckenden Maße im ganzen Bereich der Republik festgestellt sind, sind nicht genügend untersucht; zum Teil hat man Fahrlässigkeit als Brandursache angegeben."91 Die Strategie war durchsichtig: Brandfälle sollten nun vermehrt zu Brandstiftungen erklärt und als vom Westen betriebene Sabotageakte von Polizei und Justiz verfolgt werden, um gegenüber der eigenen Bevölkerung den Aufbau eines staatlichen Repressionsorgans zu rechtfertigen ${ }^{92}$.

Das MdJ stellte unmittelbar danach fest, daß die Anzahl der von den Staatsanwaltschaften verfolgten Brandsachen zwar von 4924 im Jahre 1948 auf 7522 im Jahre 1949 gestiegen sei; Gerichtsverfahren seien jedoch kaum durchgeführt worden. Außerdem sei die „Zahl der nachgewiesenen vorsätzlichen Brandstiftungen [...] im Laufe der Monate gleichmäßig niedrig geblieben“, was jedoch nach dem Regierungsbeschluß im wesentlichen auf eine „ungenügende[.] Ermittlungs- und Aufklärungstätigkeit“ zurückgeführt wurde. Mitten in der Kampagne gegen Buntmetalldiebstähle beschränkte sich das MdJ noch auf die Forderung, die Er-

86 Die Zahl der Neueingänge, die im Januar 663, im Februar 921 und im März 785 betragen hatte, ging im April auf 386 zurück. Von 1954 bis zum 30. 4. 1950 abgeurteilten Personen erhielten 510 $(28,3 \%)$ Gefängnisstrafen von über einem Jahr und Zuchthausstrafen; bei allgemeiner Kriminalität wurden damals lediglich in 10,7\% der Fälle derart hohe Strafen verhängt: siehe Gesamtergebnisse in Buntmetallstrafsachen, Stand 30. 4. 1950, BAB, DP1 VA Nr. 6208.

87 MdJ an SKK-Justizabteilung, z.H. Schichow [sic, wohl Schischow], 11.4. 1950, BAB, DP1 VA Nr. 449.

88 Protokoll der Referentenbesprechung der Hauptabteilung II, 13. 4. 1950, BAB, DP1 VA Nr. 652.

89 Vgl. die Ausarbeitung „Brandstiftungen“, 2. 2. 1950, BAB, DP1 VA Nr. 7311, Bl. 406.

$90 \mathrm{Vgl}$. Tantzscher, In der Ostzone, S. 54.

91 Beschluß der Provisorischen Regierung der DDR über die Abwehr von Sabotageakten, in: DzD II/3, S. 560. Weber, Justiz und Diktatur, S. 237, vermutet, daß auch diese Justizkampagne von sowjetischer Seite angestoßen wurde.

92 Vgl. dazu auch die Artikel von Mielke, Lange und Mayer in der "Täglichen Rundschau“ und im „Neuen Deutschland“, vgl. Tantzscher, In der Ostzone, S. 55. 
mittlungstätigkeit zu verbessern ${ }^{93}$. Als diese jedoch ihren Höhepunkt überschritten hatte, veranstaltete es am 28. März eine groß angelegte Arbeitstagung, bei der nicht nur die Leiter der Kontrollabteilungen der Justizministerien, sondern auch der Generalstaatsanwalt der DDR, die Generalstaatsanwälte der Länder sowie Vertreter der HVDVP und der ZKK anwesend waren. Dort forderte der zuständige Hauptreferent Reuter dazu auf, den Urteilen nicht nur die einschlägigen $\mathrm{Pa}$ ragraphen des Strafgesetzbuches, sondern auch die Wirtschaftsstrafverordnung zugrunde zu legen: „Das Strafmaß muß den Charakter der Wirtschaftsschädigung durch die Brandstiftung mehr in den Vordergrund stellen. Der generalpräventive Gedanke ist sowohl bei grobfahrlässigen Handlungen mit geringem Schaden als auch bei geringfahrlässigen Handlungen mit großem Schaden stärker hervorzukehren." Entscheidend für das Strafmaß sollte nicht die Gefährdungsabsicht, sondern das Ausmaß der Wirtschaftsschädigung sein, um auf diese Weise möglichst harte Strafen zu rechtfertigen ${ }^{94}$.

Mit dieser Tagung war der Startschuß für eine mit der Bekämpfung der Buntmetalldiebstähle vergleichbare Kampagne gefallen. Nun fanden auf Anordnung des $\mathrm{MdJ}$ auch in den Ländern entsprechende Schulungen statt, denen das in der „Neuen Justiz“ veröffentlichte Referat Reuters zugrunde gelegt wurde. Eine im Justizministerium gebildete Kommission für Brandsachen trat im Juni zusammen und entwarf im Einvernehmen mit dem DDR-Generalstaatsanwalt eine Rundverfügung, derzufolge besondere Brandstaatsanwälte zu bestellen und Staatsanwälte und Gerichte im Rahmen von Schulungen auf die gesetzlichen Grundlagen und die Notwendigkeit härterer Strafen hinzuweisen waren ${ }^{95}$. Trotz weiterer, gemeinsam mit der Volkspolizei durchgeführter Tagungen zeitigte dieses massive Vorgehen nur begrenzte Erfolge. Zwar sanken die Brandsachen im Verlauf des Jahres 1950, die Anzahl der verurteilten Personen stieg von 538 im ersten auf 817 im zweiten Halbjahr, und die Gerichte warfen in zunehmendem Maße anstelle von Geldstrafen Freiheitsstrafen aus. Jedoch wurde nach wie vor der prozentuale Anteil der Freisprüche als zu hoch erachtet, und die Brandstiftungsdelikte gingen keineswegs in demselben Maße zurück wie die allgemeine Kriminalität ${ }^{96}$. Daher sah es das MdJ auch im Juni 1951 als erforderlich an, eine erneute Rundverfügung dem Thema „Brandstiftung“ zu widmen"7. Der Mißerfolg dieser Kampagne läßt sich wahrscheinlich damit erklären, daß die Aufklärung von Brandsachen schwieriger war als von anderen Straftaten; außerdem kamen 1950 weitere Justizschwerpunkte hinzu - Verfahren wegen Verstoßes gegen das Handelsschutzgesetz ${ }^{98}$ und Verfahren im Zusammenhang mit den Wahlen -, die im Zweifelsfall als wichtiger erachtet wurden.

93 Brandstiftungen, 2. 2. 1950, BAB, DP1 VA Nr. 7311, Bl. 406-408.

94 Reuter, Brandstifter, S. 118.

95 Bericht über die Tätigkeit des MdJ und der Justizministerien der Länder im 1. Halbjahr 1950, BAB, DP1 SE Nr. 3361; Rundverfügung Nr. 83/50, 23. 6. 1950, BAB, DP1 VA Nr. 6283,Bl. 135137.

96 Bericht des MdJ über die Tätigkeit der Staatsanwaltschaften und Gerichte im 2. Halbjahr 1950, BAB, DP3 I Nr. 133.

97 Rundverfügung Nr. 88/51, 11. 6. 1951, BAB, DP1 VA Nr. 6284, Bl. $111 \mathrm{f}$.

98 Vgl. dazu Abschnitt 3 dieses Kapitels. 
Die Justizsteuerung wurde 1950/51 zwar intensiviert; ihrer Wirksamkeit waren aber vor allem durch die lückenhafte Berichterstattung Grenzen gesetzt. Wie der Fall der „Werdauer Oberschüler" vom Oktober 1951 zeigt, wurde das MdJ auch über politische Strafprozesse oftmals erst im nachhinein unterrichtet, so daß justizsteuernde Eingriffe vor der Urteilsverkündung von seiner Seite aus so gut wie unmöglich waren 99 . Hinzu kam, daß auch das Berichtswesen teilweise fremdgesteuert war. Die SKK-Justizabteilung erhielt Berichte über die politisch relevante Rechtsprechung nicht nur automatisch zugeschickt; sie erteilte auch regelrechte Berichtsaufträge, die teils laufend, teils periodisch und teils ad hoc zu erledigen waren. Zwar hatte der Umfang des Schriftverkehrs zwischen der Rechtsprechungsabteilung und Karlshorst gegenüber der Zeit vor 1949 abgenommen, aber noch immer band die Erstellung von Berichten für die sowjetische Kontrollbehörde Arbeitskräfte, die bei den anleitenden Tätigkeiten fehlten. Umgekehrt wurde über derartige Berichtsaufträge auch die Richtung der Justizsteuerung vorgegeben. Dies scheint vor allem bei der Rechtsprechung im Hinblick auf das Volkseigentum der Fall gewesen zu sein. Denn Titow forderte am 16. Januar 1951 einen diesbezüglichen knappen Bericht für einen Vortrag bei General Tschujkow, der von Böhme sieben Tage später überreicht wurde ${ }^{100}$. Korobow war trotz der aus Sicht des MdJ unerfreulichen Ergebnisse damit zufrieden, erteilte jedoch gleichzeitig weitere Überprüfungsaufträge ${ }^{101}$. Das sowjetische Interesse an diesem Gebiet der Rechtsprechung war so groß, daß Titow am 14. Mai 1951 nach einem weiteren entsprechenden Bericht verlangte, den das MdJ am 14. Juni bzw. 13. August auch lieferte ${ }^{102}$. Vor diesem Hintergrund wurde in der SKK auch darüber nachgedacht, der Justiz mit einem Gesetz zum Schutz des Volkseigentums ein effektiveres Mittel als bisher zur Bekämpfung von Straftaten zur Verfügung zu stellen. Jedenfalls wollte Karlshorst vom MdJ wissen, ob man dort ein derartiges Gesetz für notwendig erachte ${ }^{103}$. Lediglich Hauptreferent Reuter hielt die bisherigen Bestimmungen (insbesondere die Wirtschaftsstrafverordnung und SMAD-Befehl Nr. 160) für völlig ausreichend; Böhme und Weiß jedoch sprachen sich ausdrücklich für ein solches Gesetz aus. Freilich sollte es noch bis zum 2. Oktober 1952 dauern, bis das Gesetz zum Schutze des Volkseigentums verabschiedet wurde. Für diese Verzögerung, die auch andere Arbeiten bei der Justizgesetzgebung betraf, war Weiß zufolge vor allem das sowjetische Bedürfnis verantwortlich, „das Deut-

99 Dies war ein politischer Prozeß gegen 19 Jugendliche aus Werdau, die am 3. Oktober 1951 vom Landgericht Zwickau zu Zuchthausstrafen zwischen 2 und 15 Jahren verurteilt wurden: Siehe dazu das folgende Unterkapitel.

100 Auszug aus der Aktennotiz über die Besprechung bei der SKK am 16.1. 1951, BAB, DP1 VA Nr. 332, Bl. 177; Auszug aus der Niederschrift über die Rücksprache bei der SKK am 23. 1. 1951, ebenda, Bl. 178 .

101 Ebenda, und MdJ an SKK-Justizabteilung, 22. 1. 1951, ebenda, BI. 159-166, hier 165.

102 Zwei Vermerke Böhmes, 24. 5. 1951, BAB, DP1 VA Nr. 390; die Berichte vom 14.6. und 13. 8. 1951 ebenda.

103 Auszug aus der Niederschrift über die Rücksprache bei der SKK am 23. 1. 1951, BAB, DP1 VA Nr. 322, Bl. 178; vgl. auch Vermerk Böhmes, 24. 5. 1951, BAB, DP1 VA Nr. 390: „Herr Oberst Titow fügte noch hinzu: Ihn interessiert auch die entsprechende Gesetzgebung in den Ländern, auch möchte er wissen, was nach unserer Meinung zum Schutze des Volkseigentums in der Gesetzgebung noch fehlt, ob wir neue Gesetze für notwendig halten, ob sich aus der Praxis deren Notwendigkeit ergeben hat usw.". 
sche Gespräch [sic] nicht zu stören" 104 . Trotz des Abbaus sowjetischer Interventionen in Justizangelegenheiten zeigt diese Episode, daß das Justizministerium sowohl im Hinblick auf die Kontrolle der Justiz als auch auf die damit eng verbundene Justizgesetzgebung nach wie vor elementar von Karlshorst abhängig blieb.

\section{Die Rolle des MdJ bei der Justizsteuerung: Kooperation und Konkurrenz mit dem Obersten Gericht und der Obersten Staatsanwaltschaft}

Mit der personellen und institutionellen Etablierung des Obersten Gerichts und der Obersten Staatsanwaltschaft im Verlauf des Jahres 1950 verlor das Justizministerium seine exklusive Rolle als justizsteuernde Zentralinstanz. Die Zussammenarbeit der drei zentralen Justizorgane war jedoch weder normativ noch durch interne verbindliche Absprachen geregelt. Selbst Benjamin schrieb rückblickend, daß „das Gleichgewicht zwischen den bis dahin [November 1950] bestehenden drei zentralen Justizorganen gestört und eine neue Ordnung nicht recht gefunden wurde“105. Wenn Andreas Gängel deren anfängliches Zusammenwirken als „Experiment“ bezeichnet, das das Ziel verfolgt habe, „Erfahrungen zur Vervollkommnung der zentralen Leitung in der Justiz zu sammeln"106, so suggeriert dies eine bewußte Versuchsanordnung auf seiten der Verantwortlichen. Davon kann jedoch zwischen 1950 und 1953 keine Rede sein. Das Verhältnis war vielmehr sowohl von persönlichen $\mathrm{Zu}$ - und Abneigungen sowie Kompetenzkonflikten als auch vom $Z$ wang zur Kooperation geprägt.

Zwischen Oberstem Gericht und Oberster Staatsanwaltschaft bestanden seit ihrer Gründung aufgrund des freundschaftlichen Verhältnisses zwischen Benjamin und Melsheimer und wegen der gesetzlich vorgeschriebenen Kooperation in erstinstanzlichen und Kassationsverfahren enge Arbeitskontakte. Bis März 1951 existierte für beide Justizorgane sogar eine gemeinsame Parteiorganisation ${ }^{107}$. Demgegenüber beeinträchtigten die wechselseitigen Animositäten zwischen Fechner auf der einen und Benjamin und Melsheimer auf der anderen Seite auch die Beziehungen ihrer Zentralbehörden zum Justizministerium erheblich. Wenngleich Melsheimer seit der Einsetzung Fechners als DJV-Präsident alles andere als freundschaftliche Gefühle gegenüber diesem empfand ${ }^{108}$, war er mit der Verselbständigung der Staatsanwaltschaft sehr viel weniger auf Kooperation mit dem MdJ angewiesen als das Oberste Gericht. Trotz Spannungen zwischen Oberster Staats-

104 Siehe Auszug aus der Niederschrift über die Rücksprache bei der SKK am 23. 1. 1951, BAB, DP1 VA Nr. 322, Bl. 178 (Böhme); Vermerk Reuters, 19. 4. 1951, ebenda, Bl. 179; Vermerk Weiß, 21. 4. 1951, ebenda, Bl. 181. Für das Volkseigentumsschutzgesetz siehe GBl. 1952, S. 982.

105 Benjamin, Zur Leitung der Rechtsprechung, S. 48.

106 Gängel, Das Oberste Gericht, S. 258. Er bezieht sich auf Benjamin, Zur Leitung der Rechtsprechung, S. $50 \mathrm{f}$.

107 Vgl. Benjamin, Aus den ersten Jahren, S. 387. Benjamin übergeht freilich die Trennung der Parteiorganisation im April 1951: vgl. Abschlußbericht der Überprüfung der SED-Grundorganisation der OStA, Juni 1951, SAPMO, DY 30 IV 2/13/419.

108 Siehe Kap. B.II.2. 
anwaltschaft und Justizministerium wurden daher die heftigsten Konflikte zwischen Fechner und Benjamin ausgetragen.

Deren wechselseitige Antipathie ging auf die Jahre 1948/49 zurück, als der ehemalige sozialdemokratische Parteifunktionär in der DJV auf die radikale Kommunistin getroffen war. Weitere Gegensätze kamen hinzu: Benjamin hatte sich als eine der wenigen kommunistischen Juristen seit 1945 intensiv um die Umwandlung des Justizwesens bemüht, Kommunisten gefördert und entsprechend hart gearbeitet; Fechner hingegen war als Nicht-Jurist von der SED-Führung und der Besatzungsmacht in die Rolle des DJV-Präsidenten gedrängt worden, hatte vor allem ehemalige Sozialdemokraten herangezogen und die fachliche Arbeit weitgehend anderen überlassen. Fechner muß sich intellektuell und fachlich seiner damaligen Abteilungsleiterin unterlegen gefühlt haben; zudem stieß ihn deren Radikalität ab, so daß er sie bereits $1948 / 49$ aus seiner Behörde entfernen wollte ${ }^{109}$. Wolfgang Weiß zufolge verfolgte Fechner Hilde Benjamin "mit besonderem Haß" und versuchte, ,ihre manchmal etwas schroffe Art“ zum Anlaß zu nehmen, um sie in einer Abteilungsleiterbesprechung zu diskreditieren ${ }^{110}$. Ein wesentlicher Aspekt von Fechners internen Angriffen gegen Benjamin nach 1949 waren ihre überaus harten Urteile: So bezeichnete er das de facto unter ihrer Leitung stehende Oberste Gericht als „Scharfmacher“, und nach Verkündung des „Neuen Kurses“ führte er die „Überspitzungen“ der vorangegangenen Zeit auf die „Anklagepolitik der Staatsanwaltschaft" und die „Urteile[.] des Obersten Gerichts" zurück ${ }^{111}$. Vor diesem Hintergrund verfolgte er nach 1949 das Ziel, seine Rivalin vollständig aus der Justiz zu verdrängen: „Die Benjamin“, so hoffte er, „wird bald ausgespielt haben." 112 Worauf sich derartige Hoffnungen gründeten, bleibt angesichts der realen Machtverteilung unklar.

Die persönlichen Animositäten zwischen Fechner auf der einen und Benjamin sowie Melsheimer auf der anderen Seite erfaßten auch deren Behörden und führten zu einem teilweise heftigen Schlagabtausch. So übersandte Schumann am 27. Juni 1950 dem MdJ die Abschrift einer Entscheidung gegen einen Volkspolizisten, der wegen Gefangenenbefreiung verurteilt worden war. „Im Hinblick auf die häufigen Entweichungen von Gefangenen und die schwerwiegenden strafrechtlichen Folgen für das Aufsichtspersonal“, so der Präsident des Obersten Gerichts in seinem Begleitschreiben, „wird angenommen, daß diese Entscheidung für Belehrungszwecke des Personals der Strafvollzugsanstalten von Interesse ist. " ${ }^{113}$ In

109 Vernehmungsprotokoll des Zeugen Werner Fischl, 1.4. 1954, BStU, MfS AU 307/55, Bd. 2, Bl. $63 \mathrm{f}$.

110 Bericht von Weiß, 11. 2. 1954, BStU, MfS AU 307/55, Bd. 5a, Bl. 309. Vgl. auch Aktenvermerk über Unterredung mit Weiß am 11. 2. 1954, BStU, MfS AU 307/55, Bd. 2, Bl. 52.

11 Vermerk betr. Fechner, o.D., o.V., BStU, MfS AU 307/55, HA/GA Bd. 1, Bl. 33; Bericht Scheeles, o.D., BStU, MfS AU 307/55, Bd. 6, Bl. 189. Schumann berichtete, daß Fechner im Zusammenhang mit einem Verfahren des Obersten Gerichts gegen einen Teilnehmer am Aufstand vom 17. Juni geäußert habe: „Ihr werdet zu scharf.“ Siehe Aktenvermerk über eine Unterredung mit Schumann am 26. 1. 1954, ebenda, Bd. 2, Bl. 22.

112 Vermerk betr. Fechner, o.D., o.V., BStU, MfS AU 307/55, HA/GA Bd. 1, Bl. 35. Dort wird Fechner auch mit den Worten zitiert: „Sie [Benjamin] ist zwar keine Jüdin, aber man könnte bequem 3 aus ihr machen." Vgl. auch Brentzel, Machtfrau, S. 235, die sich für die Fechner-Äußerung über das baldige Ausscheiden Benjamins auf eine Unterredung mit Götz Berger beruft.

113 Schumann an MdJ, 27. 6. 1950, BStU, MfS AU 307/55, Bd. 5a, Bl. 290. 
der damaligen Auseinandersetzung um die Unterstellung des Strafvollzugs ${ }^{114}$ wies Fechner den Vorwurf, die Haftanstalten unzureichend gesichert zu haben, nicht nur „energisch“ zurück, sondern fügte auch noch hinzu: „Ich kann mir nur denken, daß Sie zu der Formulierung eines solchen Satzes kommen, weil Sie die Ihnen von uns übersandten Berichte nicht genügend studiert haben. Ich muß es mir verbitten, daß Sie, ohne Studium der Unterlagen, eine solche Behauptung aufstellen. "115 Schumann zeigte sich von der Form dieses Schreibens „befremdet" und verteidigte seinen Schritt vom 27. Juni, den er „angesichts der noch immer vorkommenden Entweichungen schwerer Wirtschaftsverbrecher" unternommen habe ${ }^{116}$. Zwar lenkte Fechner am 8. Juli schließlich ein; seine erste Überreaktion deutet jedoch darauf hin, daß er von der Vorstellung beherrscht war, das Oberste Gericht arbeite gegen das MdJ117. Schumann versuchte sogar, aus diesem kleinlichen Konflikt für sich Kapital zu schlagen, indem er den Schriftwechsel der SKK-Justizabteilung übersandte ${ }^{118}$.

Daß auch das Verhältnis zwischen MdJ und Oberster Staatsanwaltschaft gestört war, zeigt eine nicht minder heftige Kontroverse vom Herbst 1951. Nachdem Melsheimer gegenüber Fechner im März 1951 die Teilnahme der Staatsanwaltschaft an einem vom MdJ vorgeschlagenen Wettbewerb der Gerichte zur Reduzierung der Anzahl der liegengebliebenen Strafsachen abgelehnt hatte119, befürwortete er auf der Arbeitstagung der Obersten Staatsanwaltschaft am 21. September einen solchen Wettbewerb. Gleichzeitig sprach er sich gegen Wettkämpfe wie den vom Frühjahr aus, bei denen angeblich „die Zahl der Todesurteile oder die Zahl der auf Zuchthaus lautenden Urteile bewertet würden"120. Warum Melsheimer diesen unzutreffenden Vorwurf gegenüber dem Justizministerium erhob, ist nicht ganz klar; er erreichte damit jedenfalls, daß Fechner sich echauffiert an Anton Plenikowski wandte, um sich über die Äußerung Melsheimers zu beschweren, die er zu Recht als „eine Herabsetzung unserer Arbeit“ bezeichnete ${ }^{121}$. Wieder sah sich Fechner der Attacke eines Gegenspielers ausgesetzt, die er diesmal mit Hilfe eines mächtigeren Verbündeten abwehren wollte.

Fechner schränkte außerdem von sich aus die Kommunikation seiner Mitarbeiter mit den beiden anderen zentralen Justizorganen ein. In der Dienstbesprechung vom 3. August 1951 verbot er Angestellten des MdJ, insbesondere Abteilungsund Hauptabteilungsleitern, ohne seine Genehmigung an Konferenzen „bei anderen Ministerien oder Behörden" - gemeint waren das Oberste Gericht und die

114 Siehe dazu Kap. B.V.3.

115 Fechner an Schumann, 3.7. 1950, BStU, MfS AU 307/55, Bd. 5a, Bl.291; auch in: DP1 VA Nr. 5805.

116 Schumann an Fechner, 5. 7. 1950, ebenda.

117 Fechner an Schumann, 8. 7. 1950, ebenda.

18 Schumann an Titow, 15. 7. 1950, BStU, MfS AU 307/55, Bd. 5a, Bl. 289. Zwar übersandte Schumann den Briefwechsel auf die Bitte Titows hin; dieser kann von der Angelegenheit jedoch nur von Schumann zuvor erfahren haben.

119 Melsheimer an Fechner, 5. 3. 1951, BAB, DP1 VA Nr. 6578.

120 Vermerk von Reinartz, 3. 10. 1951, BAB, DP1 SE Nr. 3321; vgl. auch den Vermerk Reuters, 2. 10. 1951, ebenda.

121 Fechner an Plenikowski, 5. 10. 1951, ebenda. Er fügte die Vermerke von Reinartz und Reuter als Belege bei. Über die Reaktion Plenikowskis ist nichts bekannt. 
Oberste Staatsanwaltschaft - teilzunehmen ${ }^{122}$. Böhme berichtete sogar, daß Fechner die Verbindung zum Obersten Gericht insgesamt „sabotiert“ und sogar Telefongespräche nach dort untersagt habe ${ }^{123}$. Offensichtlich war sein Verbot nicht sehr wirkungsvoll: Denn zumindest die Fechner-Gegner gingen auch gegen den Willen ihres Ministers zu den entsprechenden Tagungen, soweit sie davon wußten. Der Justizminister wiederum sorgte bereits oft im Vorfeld solcher Besprechungen durch die Unterdrückung und Geheimhaltung der Einladungen dafür, daß die MdJ-Angestellten nicht teilnehmen konnten ${ }^{124}$. Das Unterbinden derartiger Arbeitskontakte zeigt erneut Fechners Unterlegenheitsgefühl angesichts der größeren Fachkompetenz Melsheimers und Benjamins und deren engeren Verbindung zum ZK der SED. Durch die Abschottung seines Ministeriums wollte er vor allem verhindern, daß Interna nach außen drangen und ihn diskreditierten - ein angesichts der MfS-Spitzel im MdJ von vornherein aussichtsloses Unterfangen. Das Mißtrauen des Justizministers gegenüber Melsheimer und Benjamin war berechtigt: Wie diese nach dessen Verhaftung angaben, hatten sie sowohl dem ZK als auch der SKK zwischen 1950 und 1953 Mitteilungen über Fechner und das MdJ zukommen lassen ${ }^{125}$.

Auch auf die schriftliche Einladung Schumanns zur Arbeitstagung der Oberlandesgerichtspräsidenten im November 1951 reagierte der Justizminister äußerst pikiert: „Ich bin der Meinung“, so Fechner am 13. November, „daß Sie in $\mathrm{Zu}$ kunft, wenn Sie die Absicht haben, die mir unterstellten Richter einzuladen, mich mit genauerer Information versehen möchten." Denn anders als ihm ursprünglich mitgeteilt, erstrecke sich die Konferenz auf zwei Tage, was einen dreitägigen Arbeitsausfall für die Richter bedeute, die bereits zwei andere Tagungen im November besuchen müßten. Das Thema - „Rechtsprechung und Überbau“ - sei zwar außerordentlich wichtig, aber er halte eine kleinere Teilnehmerzahl für sinnvoller ${ }^{126}$. Durch diese - von Schumann entschieden zurückgewiesenen ${ }^{127}-$ Vorwürfe verdeutlichte Fechner, daß er in der direkten Einladung der Mitglieder der höchsten Landesgerichte eine Einmischung in seinen Zuständigkeitsbereich als Dienstvorgesetzter des Gerichtspersonals sah. Und darauf reagierte Fechner allergisch. Zur Schlichtung dieses Streits wurde die Abteilung Staatliche Verwaltung hinzugezogen, die damals noch in Fechners Sinne entschied ${ }^{128}$. Nach seiner Auffassung

122 Bericht von Weiß über die Abteilungsleitersitzung am 3. 8. 1951, BStU, MfS AIM 6279/57, TII, Bl. 19; vgl. auch Protokoll der Abteilungsleitersitzung am 3. 8. 1951, BAB, DP1 VA Nr. 1117, Bl. 1, und das Vernehmungsprotokoll Fechners, 19. 8. 1953, BStU, MfS AU 307/55, Bd. 1, Bl. 124.

123 Aktenvermerk, Betr.: Rücksprache des Gen. Blumenstein mit Böhme und Grube, 28. 7. 1953, ebenda, Bl. 58.

124 Aktenvermerk über eine Unterredung mit Schumann am 26.1. 1954, 27. 1. 1954, BStU, MfS AU 307/55, Bd. 2, Bl. 22; Ausarbeitung o.D., o.V. [vermutlich Ausführungen Grubes], ebenda, Bd. 7, Bl. $289 \mathrm{f}$.

125 Zwei Aktennotizen, Betr.: Rücksprache Oberst Scholz mit Melsheimer und Benjamin am 20.7. 1953, 21. 7. 1953, ebenda, Bd. 1, Bl. 36, 38.

126 Schumann an Fechner, 6. 11. 1951, BStU, MfS AU 307/55, Bd. 5a, Bl. 303; Fechner an Schumann, 13. 11. 1951, ebenda, Bl. 302, und in: BAB, DP1 VA Nr. 5806.

127 Schumann an Fechner, 22. 11. 1951, BAB, DP1 VA Nr. 6584, Bl. 188.

128 Vgl. Vernehmungsprotokoll Fechners, 19.8. 1953, BStU, MfS AU 307/55, Bd. 1, Bl. 124. Siehe auch Benjamin, Die Tätigkeit des Obersten Gerichts von 1949 bis 1952, BAB, DP1 VA Nr. 6656. Darin berichtet sie, daß die Abteilung Staatliche Verwaltung das Oberste Gericht in diesem Zusammenhang darauf hingewiesen habe, „daß wir mit einer solchen Arbeitsmethode doch in die 
hatte das Oberste Gericht „allein auf dem Wege der Rechtsprechung die Arbeit der Gerichte mit zu beeinflussen"; alles andere betrachtete er als Übergriff in seinen Amtsbereich ${ }^{129}$.

Als nach dem 17. Juni 1953 Fechner die Auffassung des CDU-Hauptvorstands mitgeteilt wurde, daß das Oberste Gericht und die Oberste Staatsanwaltschaft wieder dem Justizminister unterstellt werden sollten, befürwortete er dies zwar unter Verweis auf das sowjetische Vorbild nicht, wollte aber den Vorrang des Justizministeriums festschreiben. Als Alternative war nach den Ausführungen Scheeles für Fechner eine Koordinierungstelle für die drei Justizorgane denkbar, die er gerne leiten wollte ${ }^{130}$. Auch wenn man berücksichtigen muß, daß Scheele in diesem Bericht für die Staatssicherheit darauf bedacht war, seinen ehemaligen Förderer in ein nicht allzu schlechtes Licht zu rücken, so erscheinen diese Aussagen doch vor dem Hintergrund von Fechners Bestrebungen und Aktivitäten plausibel: Zwar wollte er keine der institutionellen Übernahmen aus der Sowjetunion rückgängig machen, sich aber - unter Ausschaltung von Benjamin, Schumann und Melsheimer - einen maßgeblichen Einfluß an der Spitze des Justizwesens sichern.

Trotz all dieser Auseinandersetzungen waren die drei zentralen Justizorgane zur Kooperation gezwungen, wenn sie ihre Steuerungsfunktionen erfüllen wollten. So waren bei fast allen größeren Tagungen und Besprechungen des Obersten Gerichts, der Obersten Staatsanwaltschaft und des MdJ Vertreter der jeweils anderen Behörden anwesend; selbst an der zwischen Fechner und Schumann so umstrittenen Tagung der Oberlandesgerichtspräsidenten im November 1951 nahmen sechs Vertreter des Justizministeriums teil, und nicht, wie Fechner ursprünglich angekündigt hatte, nur ein Mitglied der Schulungsabteilung ${ }^{131}$. Neben wechselseitigen Tagungsbesuchen gaben ab Januar 1951 das Justizministerium, das Oberste Gericht und die Oberste Staatsanwaltschaft das juristische ,Zentralorgan' der DDR, die „Neue Justiz“, gemeinsam heraus ${ }^{132}$. Am 22. Dezember 1950 hatte das Justizministerium dem Präsidenten des Obersten Gerichts und dem Generalstaatsanwalt einen entsprechenden Vorschlag unterbreitet: angesichts der Etablierung der beiden zentralen Justizorgane „als selbständige Instanzen neben dem Ministerium der Justiz" und der Veröffentlichung von Entscheidungen des höchsten DDR-Gerichts in der "Neuen Justiz" war für Fechner deren Beteiligung an der Herausgabe der Zeitschrift nur eine logische Schlußfolgerung ${ }^{133}$. Schumann und Melsheimer stimmten zu, so daß am 12. Januar 1951 eine erste gemeinsame Be-

Zuständigkeit des Justizministeriums eingriffen und daß es Sache des Ministeriums wäre, derartige Veranstaltungen durchzuführen".

129 Bericht Scheeles, BStU, MfS AU 306/55, Bd. 6, Bl. 175 f.

130 Ebenda, Bl. $176 \mathrm{f}$.

131 Schumann an Fechner, 22. 11. 1950, BAB, DP1 VA Nr. 6584; Fechner an Schumann, 13. 11. 1951, BAB, DP1 VA Nr. 5806.

132 Siehe die Notiz „Die Herausgeber der ,Neuen Justiz““ in: NJ 5 (1951), S. 4. Die „Neue Justiz“ wurde seit 1947 von der DJV herausgegeben; die Besetzung des Redaktionsausschusses der NJ war anfangs zwischen SMAD und SED auf der einen und Schiffer auf der anderen Seite umstritten; obwohl sich die SED mit Hilfe der SMAD durchsetzen konnte, wurde sie erst nach und nach zu einem Organ, das eine entsprechende parteipolitische Ausrichtung aufwies.

133 Fechner an Schumann und Melsheimer, 22. 12. 1950, BAB, DP1 SE Nr. 3356. Bemerkenswert ist in diesem Zusammenhang, daß Weiß am 4. 1. 1951 Benjamin eine Abschrift des Briefes vom 22. 12. 1950 übersandte (ebenda): Möglicherweise hatte Weiß den Brief für Fechner auf Benjamins Anregung hin konzipiert. 
sprechung über die Zeitschrift stattfinden konnte ${ }^{134}$. Dabei wurde unter anderem festgelegt, eine aus Fechner, Schumann, Benjamin, Melsheimer und Weiß bestehende Redaktionskommission zu bilden, die sich monatlich treffen sollte, um den Inhalt jeder einzelnen Nummer zu besprechen. Fechner benannte Scheele als seinen Vertreter, so daß er selbst an den Sitzungen kaum teilnahm. Unter den anderen Festlegungen ist besonders die Entscheidung hervorzuheben, Artikeln und Gesetzen aus der Sowjetunion und den anderen Volksdemokratien mehr Raum zu widmen. Mit der Erweiterung des Herausgebergremiums und der gemeinsamen Steuerung der Justiz über die Zeitschrift war somit auch eine verstärkte Sowjetisierung verbunden.

Seit September 1950 erließen MdJ und Oberste Staatsanwaltschaft zudem eine Reihe gemeinsamer Rundverfügungen, die Gerichte und Staatsanwaltschaften gleichermaßen betrafen. Den Anfang machte Rundverfügung Nr. 121/50 vom 14. September, die im Zusammenhang mit den Wahlen erging und die politische Strafrechtsprechung verschärfte; in kurzem Abstand folgten die gemeinsamen Rundverfügungen vom 21. September über Verfahren nach dem Handelsschutzgesetz und vom 26. September über die Bestrafung des ungesetzlichen Überschreitens der Staatsgrenzen und der Demarkationslinie ${ }^{135}$. Auch nach der völligen Herauslösung der Staatsanwaltschaft aus der Justizverwaltung mit der Verordnung vom 27. September 1951 wurde die Praxis gemeinsamer Rundverfügungen weiter beibehalten ${ }^{136}$. Die Notwendigkeit praktischer Kooperation war somit auch bei dieser Anleitungsform sehr viel größer als eventuelle Rivalitäten an der Spitze der jeweiligen Behörde.

Auch in wichtigen juristischen Einzelfragen, die insbesondere im Zusammenhang mit der Kassationsrechtsprechung auftauchten, waren enge Abstimmungen zwischen dem Obersten Gericht, dem MdJ und der Obersten Staatsanwaltschaft unumgänglich. So wandte sich beispielsweise Nathan am 2. April 1951 in einer Kassationsangelegenheit, die die umstrittene Frage der Staatshaftung betraf, an Melsheimer persönlich und schlug vor, die Angelegenheit zunächst intern mit ihm, Benjamin und dem Leiter des SED-Justizsektors Kulaszewski zu besprechen $^{137}$. Weitgehende Kooperation herrschte auch beim Austausch notwendiger Informationen: So wurden etwa die Oberlandesgerichte angewiesen, sämtliche Urteile dem Obersten Gericht zu übersenden ${ }^{138}$, und das Oberste Gericht ließ alle seine Urteile der Kontrollabteilung des Justizministeriums zukommen ${ }^{139}$. Das MdJ seinerseits sorgte dafür, daß die Gerichte die erstinstanzlichen Urteile des Obersten Gerichts zum Gegenstand von Schulungen machten ${ }^{140}$.

134 Schumann an Fechner, 9. 1. 1951, BAB, DP1 VA Nr. 6592, Bl. 4; ein entsprechendes Schreiben Melsheimers ist nicht überliefert; der erkrankte Melsheimer schickte aber Hildegard Heinze zu dem Treffen am 12. 1. 1951: siehe Vermerk vom 18. 1. 1951, BAB, DP1 SE Nr. 3356.

135 Rundverfügungen Nr. 121/50 vom 14. 9. 1950, Nr. 122/50 vom 21. 9. 1950, Nr. 126/50 vom 26.9. 1950 in: BAB, DP1 SE Nr. 1199, DP1 VA Nr. 6283, Bl. 198-201.

136 Siehe u. a. die Rundverfügungen Nr. 25/52 vom 3. 1. 1952, Nr. 26/52 vom 31. 1. 1952 und Nr. 36/ 52 vom 23. 2. 1952, alle in: ANBl. 1952, S. 37-40, 40f., 49-51.

137 Nathan an Melsheimer, 2. 4. 1951, BAB, DP1 VA Nr. 5591.

138 So Nathan an Benjamin, 7.1. 1952, BAB, DP1 VA Nr. 5597.

139 So ein Beschluß des Präsidiums des Obersten Gerichts vom 20. 4. 1950, BAB, DP2 Nr. 339.

140 Siehe Kap. B.VII.5. 
Erste Ansätze zu einer Formalisierung der Zusammenarbeit der drei obersten Justizorgane ergaben sich aus den Schlußfolgerungen, die aus eklatanten Steuerungsmängeln im Zusammenhang mit dem Prozeß gegen 19 Oberschüler aus Werdau gezogen wurden. Letztere hatten seit Herbst 1950 in Flugblättern unter anderem gegen die Volkskammerwahl von 1950 sowie gegen das Todesurteil im Fall des Oberschülers Josef Flade protestiert und zum Widerstand gegen das Regime aufgerufen. Nachdem sie im Mai 1951 verhaftet und anschließend vom MfS verhört worden waren, wurde ihnen am 3. und 4. Oktober 1951 vor dem Landgericht Zwickau der Prozeß gemacht. Das Gericht verurteilte sie zu Zuchthausstrafen zwischen 15 und zwei Jahren ${ }^{141}$. Trotz aller Geheimhaltungsbemühungen drangen Informationen nach außen, so daß Grotewohl am 2. Oktober 1951 aus dem West-Berliner „Tagesspiegel“ über das bevorstehende Verfahren und die vorgesehenen harten Strafen erfuhr. Seine Bemühungen, über Fechner den Prozeß zu verhindern oder zumindest eine Aussetzung der Urteile zu veranlassen, waren erfolglos. Denn der nicht informierte Justizminister mußte erst Hauptabteilungsleiter Böhme beauftragen, nach Zwickau zu fahren, um eine Verschiebung des Urteils zu erreichen. Als Böhme am 4. Oktober vormittags dort eintraf, waren die Urteile jedoch bereits verkündet worden ${ }^{142}$. Die anschließende Untersuchung ergab, daß weder die Hauptabteilung Justiz beim sächsischen Ministerpräsidenten noch die SED-Landesleitung unterrichtet worden waren. Von den zentralen staatlichen Instanzen hatten lediglich das MfS und die Oberste Staatsanwaltschaft von dem Prozeß erfahren. Denn das MfS hatte die Landesstaatsanwaltschaft Sachsen angewiesen, bei Verfahren, ,in denen die Voruntersuchung beim Ministerium für Staatssicherheit liegt, weder eine Stelle der Staatsverwaltungen noch eine Stelle der Partei zu informieren"143. Der Vorgang führte der SED-Führung deutlich die Gefahr vor Augen, daß bei politischen Prozessen MfS und Staatsanwaltschaft die Rechtsprechung nach eigenem Gutdünken steuerten. Um dies in Zukunft bei drohenden harten Strafen zu verhindern und den Primat der Politik zu sichern, faßte das Sekretariat des ZK am 8. Oktober 1951 folgenden Beschluß: „Wenn voraussichtlich Urteile mit mehr als 10 Jahren gefällt werden sollen, ist vorher eine Stellungnahme der Genossen Fechner, Melzheimer [sic], Benjamin und einem Vertreter [sic] der Abteilung Staatliche Verwaltung erforderlich."144 Damit war die sogenannte "Justizkommission“ aus der Taufe gehoben worden, die sich in dieser Zeit also aus dem Justizminister, dem DDR-Generalstaatsanwalt, dem ranghöchsten SED-Mitglied beim Obersten Gericht und einem zuständigen ZK-Mitarbeiter zusammensetzte ${ }^{145}$. Es handelte sich dabei um die Sonderform einer von der SED-

${ }^{1+1}$ Vgl. dazu u.a. Beyer, Prozeß gegen die Werdauer Oberschüler; Geißler, Politischer Strafprozeß gegen Oberschüler in Werdau; Werkentin, Strafjustiz im politischen System der DDR, S. 104106.

142 Vermerk der Abteilung Staatliche Verwaltung der SED-Landesleitung Dresden, 18. 10. 1951, zit. in: Wendel, Ulbricht als Richter und Henker, S. 119.

${ }_{143}$ Bericht über den Zwickau durchgeführten Prozeß gegen die 19 Schüler der Oberschule Werdau, 20. 11. 1951, zit. ebenda, S. 122-126, das Zitat S. 125.

144 Protokoll der Sekretariatssitzung, 8. 10. 1951, SAPMO, DY 30 J IV 2/3/239, TOP 12 (Unterpunkt 5).

145 In dem Bericht vom 20.11. 1951 hieß es lediglich, daß das Sekretariat des ZK beschlossen habe, „daß alle Urteile, in denen mehr als 10 Jahre Freiheitsstrafe vorgesehen sind, einer Kommission zur Beschlußfassung vorzulegen sind“ (zit. nach Wendel, Ulbricht als Richter und Henker, S. 126). Da 
Führung verordneten Kooperation, die durch die Versammlung des politischen und juristischen Sachverstands auf höchster Ebene aus der Sicht des Regimes unangemessene Urteile verhindern sollte.

Trotz des gespannten Verhältnisses zwischen Fechner, Benjamin, Schumann und Melsheimer unterlagen praktische Fragen der Justizsteuerung eher dem Zwang zur Kooperation. In einer für die Lenkung der Rechtsprechung zentralen Frage blieb der Justizminister jedoch gegenüber den Vorstößen des Obersten Gerichts unnachgiebig: Es ging um den direkten Zugang zu den Gerichten, den er sich nach der völligen Verselbständigung der Staatsanwaltschaft und den damit verbundenen Kompetenzeinbußen nicht auch noch nehmen lassen wollte. Mit der Neuorganisation der Staatsanwaltschaft nach sowjetischem Vorbild am 27. September 1951 versiegte jedoch auch der für die Justizsteuerung unabdingbare Strom der Berichterstattung von den Staatsanwälten an die Justizverwaltung. Nicht nur der Prozeß gegen die Werdauer Oberschüler offenbarte den dadurch hervorgerufenen Informationsmangel im Justizministerium. Sowohl die Hauptabteilung Rechtsprechung im MdJ als auch die Leiter der Hauptabteilungen Justiz bei den Ministerpräsidenten klagten im Oktober 1951, daß sie von den Staatsanwälten keine Anklagen aus politischen Prozessen mehr erhielten ${ }^{146}$.

Vor diesem Hintergrund sind die Auseinandersetzungen mit dem Obersten Gericht um den exklusiven Zugang des MdJ zu den unteren Gerichten zu sehen. Ausgangspunkt war eine Bitte Schumanns an das MdJ, bestimmte Justizverwaltungsstellen zur Übersendung einer Reihe von Zivilurteilen dem Obersten Gericht zu veranlassen ${ }^{147}$. Nachdem trotz zweimaliger Nachfragen Schumanns bei Hauptabteilungsleiter Böhme die Urteile am 22. Dezember immer noch nicht beim Obersten Gericht eingetroffen waren, beschwerte sich Schumann bei Fechner über die Verzögerung und kündigte an, daß er die Entscheidungen direkt von den Gerichten anfordern werde ${ }^{148}$. In einem weiteren Schreiben an den Justizminister vom selben Tag sprach er sich für eine von den drei obersten Justizorganen koordiniert geplante und durchgeführte Anleitung der Rechtsprechung aus und schlug einen Austausch der Erfahrungsberichte und Arbeitspläne vor ${ }^{149}$. In seinem erbosten Antwortschreiben monierte Fechner erstens, daß sich die erste Anfrage vom 17. November nur ganz allgemein an das Ministerium, nicht aber an ihn persönlich gerichtet habe; zweitens widersetzte er sich unter Verweis auf das neue

damit nur der Sekretariatsbeschluß vom 8. 10. 1951 gemeint sein kann, steht damit auch die $\mathrm{Zu}$ sammensetzung dieser Kommission fest, über die des öfteren gerätselt worden ist: vgl. Rottleuthner, Zur Steuerung der Justiz, S. 40; Werkentin, Strafjustiz im politischen System der DDR, S. 124.

146 Protokoll der Referentenbesprechung der Hauptabteilung II, 6. 10. 1951, BAB, DP1 VA Nr. 653, Bl. 121; Vermerk betr. Zusammenarbeit des Generalstaatsanwaltes der Republik mit dem Ministerium der Justiz, o.D., BAB, DP1 SE Nr. 3360, Bl. 259. Die Staatsanwälte übersandten zwar keine Anklagen mehr an die Justizverwaltungen; nach einem Protest Böhmes auf der Arbeitstagung der Obersten Staatsanwaltschaft am 12. Oktober einigten sich die Kontrahenten jedoch darauf, daß den Gerichten Abschriften der Anklageschriften zur Weiterleitung übergeben werden sollten: Protokoll der Arbeitstagung am 12. 10. 1951, BAB, DP1 Nr. 25, Bl. 342 f.; Protokoll der Referentenbesprechung der Hauptabteilung II, 13. 10. 1951, BAB, DP1 VA Nr. 653.

147 Schumann an MdJ, 17. 11. 1952, BStU, MfS AU 307/55, Bd. 5a, Bl. 173.

148 Schumann an Fechner, 22. 12. 1952, ebenda, Bl. $171 \mathrm{f}$. Zu den Verzögerungen siehe Vermerk Schumanns, 16. 12. 1952, ebenda, Bl. 284. Das Schreiben Schumanns an Fechner auch in: BAB, DP1 VA Nr. 5596.

149 Schumann an Fechner, 22. 12. 1952, ebenda und in: BStU, MfS AU 307/55, Bd. 5a, Bl. $169 f$. 
Gerichtsverfassungsgesetz dem Vorhaben Schumanns, sich direkt an die Gerichte zu wenden, und weigerte sich, die Arbeitspläne der Gerichte zu übersenden; drittens erklärte er sich zwar zur Zusammenarbeit mit den beiden anderen Justizorganen bei der Justizsteuerung bereit, stellte dabei aber unmißverständlich fest: „Anleitung und Anweisungen, soweit das nötig ist, können selbstverständlich an die mir unterstellten Gerichte und Justizverwaltungsstellen nur durch mich direkt erfolgen." 150 Fechner, der seinen Standpunkt auch der Abteilung Staatliche Verwaltung dargelegt hatte und diese über die Korrespondenz mit Schumann auf dem laufenden hielt ${ }^{151}$, konnte seinen exklusiven Zugang zu den Gerichten aufrechterhalten. Denn Schumann richtete weitere Anfragen im Hinblick auf bestimmte Gerichtsurteile im Januar und März 1953 nur noch an das MdJ152. Da das MdJ die Gerichte anwies, die gewünschten Urteile an das Oberste Gericht nur zu übersenden, wenn "damit keine Mehrarbeit verbunden sei“, gingen die Entscheidungen dort unvollständig und zu spät ein. Auf Nachfrage Benjamins erklärte Böhme, daß die Einschränkung in die Aufforderung an die Gerichte „auf ausdrückliches Verlangen des Ministers Fechner" eingefügt worden sei ${ }^{153}$.

In ähnlicher Weise torpedierte Fechner eine vom Obersten Gericht für März 1953 geplante Zusammenkunft der Richter der Bezirksgerichte ${ }^{154}$. Gegenüber Schumann machte er am 18. Februar geltend, daß auch das Justizministerium seit langem eine derartige Zusammenkunft plane, und plädierte für eine gemeinsame Veranstaltung155. Schumann wies dies umgehend unter Verweis auf die viel Zeit beanspruchende, schwierige Thematik der bevorstehenden Tagung des Obersten Gerichts - die Grundlagen des neuen Rechtsmittelverfahrens - zurück und ließ sich auch durch die Übersendung der Tagesordnung der MdJ-Veranstaltung nicht von seiner Meinung abbringen ${ }^{156}$. Auch die Kooperation von Oberstem Gericht und Justizministerium bei der Revision der Bezirksgerichte, zu der Fechner Schumann am 19. September 1952 ausdrücklich aufgefordert hatte ${ }^{157}$, hintertrieb der Justizminister. Zwar konnte er sie nicht völlig verhindern; indem er jedoch die angesetzten Termine für diese Überprüfungen dem Obersten Gericht zu spät mitteilte, vereitelte er oftmals dessen Beteiligung ${ }^{158}$. Fechner war teils aus berechtigter Sorge vor der Abgabe eigener Kompetenzen, teils aber auch aus persönlichen

150 Fechner an Schumann, 22. 12. 1952, ebenda, Bl. 278f.; auch in: BAB, DP1 VA Nr. 7842, Bl. $149 \mathrm{f}$.

151 Fechner an Abteilung Staatliche Verwaltung, z.H. Spank, 30. 12. 1952, ebenda, Bl. 148.

152 Schumann an MdJ, 12. 3. 1953, BAB, DP1 VA Nr. 5578; Analyse und zusammenfassender Bericht über die Tätigkeit des OG im 1. Halbjahr 1953, BAB, DP1 VA Nr. 176, Bl. 126.

153 Ebenda.

154 Dies ging aus dem Arbeitsplan hervor, den Schumann am 17. Januar 1953 dem MdJ übersandt hatte: vgl. Benjamin an Plenikowski, 2. 3. 1953, SAPMO, DY 30 IV 2/13/408.

155 Fechner an Schumann, 18. 2. 1953, BAB, DP1 VA Nr. 7843.

156 Schumann an Fechner, 20. 2. 1953, ebenda; Schumann an Fechner, 5. 3. 1953, BStU, MfS AU $307 /$ 55, Bd. 5a, Bl. $175 \mathrm{f}$. Über eine entsprechende Arbeitstagung im Obersten Gericht ist nichts bekannt.

157 Fechner an Schumann, 19. 9. 1952, BAB, DP1 VA Nr. 7842, Bl. 323. Schumann stimmte dem Vorschlag mit Schreiben vom 24. 9. 1952 zu, ebenda, Bl. 340.

158 So teilte Fechner dem Obersten Gericht etwa erst am 11. 3. 1953 mit, daß am 10./11. 3. 1953 eine Revision des Bezirksgerichts Neubrandenburg geplant sei: siehe Schumann an Fechner, 12.3. 1953, BAB, DP1 VA Nr. 5578. Vgl. auch Analyse und zusammenfassenden Bericht über die Tätigkeit des OG im 1. Halbjahr 1953, BAB, DP1 VA Nr. 176, Bl. $126 \mathrm{f}$. 
Aversionen gegen Benjamin und Schumann heraus nicht dazu bereit, das Oberste Gericht bei der direkten Anleitung der Gerichte zu beteiligen.

Das Verhältnis der drei obersten Justizorgane in der Justizsteuerung untereinander wurde in den Jahren zwischen 1950 und 1953 nicht abschließend geklärt. Der Ausgang der Konflikte in den Jahren 1952/53 verdeutlicht jedoch, daß sich ein ungefähres Gleichgewicht und eine Arbeitsteilung zwischen Oberstem Gericht und Justizministerium herausgebildet hatten: Während das Oberste Gericht weitgehend durch seine zweitinstanzliche und Kassationsrechtsprechung die unteren Gerichte anleitete, wurde dem MdJ die Möglichkeit gelassen, als den Gerichten vorgesetzte Behörde deren Rechtsprechung zu lenken. Wenngleich die Konflikte zwischen Schumann und Benjamin auf der einen und Fechner auf der anderen Seite auffällig sind, haben sie die Justizsteuerung durch die zentralen Justizorgane jedoch sehr viel weniger beeinträchtigt als eine Reihe justizfremder Instanzen, deren Tätigkeit im folgenden umrissen werden soll.

\section{Das MdJ und justizfremde Instanzen in der Justizsteuerung}

Das Justizministerium verfügte innerhalb des zentralen Staatsapparats der DDR nur über ein relativ geringes Gewicht. Ein äußeres Indiz dafür war, daß es in den offiziellen Aufzählungen der Ministerien im DDR-Gesetzblatt stets an letzter Stelle rangierte ${ }^{159} .1952$ äußerte ein Mitarbeiter des MdJ seine Besorgnis darüber, daß durch die Beibehaltung dieser Reihenfolge ein falscher Eindruck erweckt werde, und plädierte dafür, es „unter den an erster Stelle genannten Ministerien aufzuführen, deren Tätigkeit sich nicht auf einen abgegrenzten wirtschaftlichen Bereich beschränkt" ${ }^{160}$. Die Herabsetzung des Justizministeriums beschränkte sich jedoch nicht auf solche Äußerlichkeiten. Es wurde, was Abteilungsleiter Nathan im Februar 1950 sehr deutlich beklagte, auch dort, wo seine Zuständigkeit auch unter den Verhältnissen der sozialistischen Diktatur gegeben war, nämlich bei der strafrechtlichen Gesetzgebung, oftmals übergangen. Er forderte Fechner daher auf, im Ministerrat eindeutig klarzustellen, „daß Gesetzentwürfe, gleichgültig welcher Art, vor der Vorlage an die Regierung dem Ministerium der Justiz zur Zustimmung vorgelegt werden müssen, sofern in diesen Entwürfen Strafvorschriften enthalten sind“" 161 . Zwar hing die mangelnde Berücksichtigung des $\mathrm{MdJ}$ in solchen Fällen sicherlich auch damit zusammen, daß Fechner Bedenken seiner Mitarbeiter gegenüber Gesetzesvorlagen in Ministerratssitzungen nicht zur Sprache brachte und es ihm an Durchsetzungsfähigkeit mangelte ${ }^{162}$; in der Tatsache, daß das MdJ in diesen Fragen regelrecht übergangen und auch nicht an der Formulierung des zentralen Wirtschaftsstrafgesetzes zum Schutz des innerdeutschen

159 Vgl. Bekanntmachung über den Strukturplan der Provisorischen Regierung der DDR, 1. 11. 1949, in: GBl. 1949, S. 2-4, hier 4; Gesetz über die Regierung der DDR, 8. 11. 1950, GBl. 1950, S. 1135 f.; Gesetz über die Regierung der DDR, 23. 5. 1952, GBl. 1952, S. $407 \mathrm{f}$.

160 Vermerk von Artzt für Fechner, 9. 5. 1952, BAB, DP1 VA Nr. 6449.

161 Notiz Nathans für die Ministerratssitzung am 16. 2. 1950, BAB, DP1 VA Nr. 7311, Bl. $414 \mathrm{f}$.

162 Vermerk der Hauptabteilung Gesetzgebung, 18. 5. 1954, BStU, MfS AU 307/55, Bd. 5b, Bl. 49;

Bericht von Weiß, 11. 2. 1954, ebenda, Bd. 5a, Bl. 312. 
Handels beteiligt wurde ${ }^{163}$, wird seine Mißachtung durch die Staats- und Parteiführung jedoch überdeutlich.

Justizsteuerung über die Strafgesetzgebung war somit für das MdJ nur sehr eingeschränkt möglich. Jedoch gewannen justizfremde Instanzen auch erhebliche Einflüsse auf die Rechtsprechung, so daß hier das MdJ mit seinem Steuerungsanspruch ebenfalls ins Hintertreffen geriet. Bereits erwähnt wurde das MfS, das als Untersuchungsorgan in politischen Prozessen in der Nachfolge der K 5 einen sehr weitgehenden Einfluß auf den Ausgang der Verfahren ausübte ${ }^{164}$. Wie die Vorgänge im Fall der Werdauer Oberschüler gezeigt haben, nahm das MfS eine derart beherrschende Stellung in politischen Prozessen ein, daß es zeitweise mit Erfolg die Berichterstattung an die Justizverwaltung untersagte und damit dem MdJ jede Möglichkeit der Justizsteuerung nahm. Da eine derartige Weisung jedoch auch die Eingriffsmöglichkeiten der Parteiführung beeinträchtigte, kam es im Oktober 1951 aufgrund eines Sekretariatsbeschlusses zur Einrichtung der Justizkommission. Das MfS wirkte überdies durch seine für die Überwachung des Staatsapparats zuständige Hauptabteilung V auf die Justiz ein, da diese mit ihrem Referat 4/ A, bzw. ab 1955, mit Referat 5/I nicht nur die zentralen Justizorgane überwachte, sondern auch dem Einsatz der Staatsanwälte in politischen Verfahren zustimmen mußte. Vor der Ernennung, bzw. ab 1960, vor der Wahl der Richter überprüfte das MfS zudem deren politische Linientreue, so daß die Staatssicherheit auch über Steuerungsmöglichkeiten hinsichtlich des Justizpersonals verfügte ${ }^{165}$. Dies garantierte in den meisten Fällen eine im Sinne des MfS funktionierende politische Strafjustiz; Ausnahmen sind jedoch ebenfalls aktenkundig geworden: So wurde etwa in einem Prozeß am Bezirksgericht Karl-Marx-Stadt ein Angeklagter gegen den ausdrücklichen Willen des Leiters der Untersuchungsabteilung am 27. Juli 1956 auf Antrag des Staatsanwalts freigesprochen, obwohl der MfS-Offizier vorher mit allen Mitteln versucht hatte, diesen von einem entgegengesetzten Plädoyer zu überzeugen ${ }^{166}$.

Nicht nur bei den genuin politischen Strafprozessen, sondern auch bei den Verfahren nach dem sogenannten Handelsschutzgesetz büßte die Justiz Kompetenzen ein. Das "Gesetz zum Schutz des innerdeutschen Handels“ vom 21. April 1950 ging indirekt auf eine sowjetische Anweisung im Zusammenhang mit dem Ende Februar Stalin unterbreiteten Entwurf des Fünfjahrplans zurück ${ }^{167}$. Tschujkow und der Stellvertreter des politischen Beraters der SKK, Iljitschow, sagten am 7. März 1950 Pieck und Grotewohl zwar bei der Ausarbeitung des Pla-

163 Vgl. Bericht über die Tätigkeit des MdJ und der Ministerien der Länder im 1. Halbjahr 1950, BAB, DP1 SE Nr. 3361.

164 Vgl. dazu Kap. B.VII.4. Dabei waren die Kriterien zur Abgrenzung der Zuständigkeit des MfS von der der Volkspolizei unklar; welche Verfahren es an sich zog, blieb letztlich im Ermessen des MfS: vgl. Engelmann, Staatssicherheit und Kaderpolitik, S. 138-140.

165 Vgl. Vollnhals, Nomenklatur und Kaderpolitik, S. $219 \mathrm{f}$. Nach Pohl, Justiz in Brandenburg (Manuskript), S. 122 f., Anm. 210, fanden solche Überprüfungen durch das MfS seit 1950 statt. Sie bezogen sich vornehmlich auf Richter der 1. Senate. Sachakten der Hauptabteilung V des MfS bekam der Vf. beim BStU trotz eines entprechenden Antrags nicht zu sehen.

166 Siehe Aktennotizen des Staatsanwalts Schmidt vom 25. und 26. 7. 1956 sowie die Urteilsabschrift in: BStU, MfS AU 255/56, Bd. 2, Bl. 57f., 80. Bei diesem Fall muß freilich berücksichtigt werden, daß er in die kurze "Tauwetterperiode" nach dem XX. KPdSU-Parteitag fiel.

167 Vgl. Pieck an Stalin, 28. 2. 1950, in: Badstübner/Loth, Pieck-Aufzeichnungen, S. 335. 
nes sowjetische Unterstützung zu, monierten jedoch gleichzeitig, daß die DDR durch „Schmuggel nach dem Westen [...] ausgepumpt" werde, und verlangten Gegenmaßnahmen. Als ein Ergebnis der Unterredung notierte Pieck in diesem Zusammenhang: "Schaffung eines Zollamts bei der Regierung erwägen." 168 Bald danach begannen die SED-Gremien zu arbeiten, so daß am 21. März 1950 das Politbüro über einen ersten Entwurf zu einem „Gesetz zur Kontrolle des Warentransportes" zu befinden hatte. Es akzeptierte ihn jedoch nicht ${ }^{169}$, und die Abteilung Staatliche Verwaltung erarbeitete - ohne Konsultation mit dem MdJ - einen zweiten Entwurf, den es am 17. April dem Sekretariat vorlegte. In der Begründung dazu wurde auf den der DDR-Wirtschaft durch den illegalen Warenverkehr in den Westen zugefügten Schaden verwiesen, der mehr als 2 Milliarden DM jährlich betrage. Da man als neuralgische, bisher kaum kontrollierte Zone im Warenstrom West-Berlin ausmachte, sah der Gesetzentwurf eine umfassende Kontrolle des Warenverkehrs zwischen der DDR und der Viersektorenstadt sowie hohe Strafandrohungen vor (mindestens drei Jahre Gefängnis und in schweren Fällen mindestens fünf Jahre Zuchthaus und Vermögenseinziehung). Mit der Überwachung beauftragt werden sollte ein noch zu schaffendes „Amt zur Kontrolle des Warenverkehrs" ${ }^{170}$. Nach Zustimmung des Sekretariats brachte man das Gesetz binnen kurzer Zeit durch die zuständigen Gremien: Das Politbüro segnete es am 18. April ab, Regierung und Volkskammer gaben zwei bzw. drei Tage darauf ihr vorhersehbares Plazet ${ }^{171}$. Wie vom Politbüro bestimmt, wurde daraufhin beim Ministerium für innerdeutschen und Außenhandel das Amt für Kontrolle des Warenverkehrs (AKW) unter der Leitung des ehemaligen stellvertretenden Vorsitzenden der ZKK Anton Ruh errichtet ${ }^{172}$.

Nach dem Gesetz durfte eine Vielzahl von Produkten nur mit Warenbegleitscheinen zwischen der DDR und dem Ostsektor Berlins transportiert werden. Bei Zuwiderhandlung mußte das AKW die Produkte einziehen und konnte von sich aus Geldstrafen bis zum zehnfachen Wert der konfiszierten Waren verhängen. Zwar sah das Gesetz darüber hinaus hohe Gefängnisstrafen vor, hatte die damit zusammenhängenden juristischen Fragen jedoch nur ungenügend geklärt. Dies bezog sich vor allem auf das Verhältnis der vom $\mathrm{AKW}$ verhängten Geldstrafen und der von den Gerichten zu verhängenden Gefängnis- und Zuchthausstrafen, auf die genaue Abgrenzung der „besonders schweren“ von den anderen Fällen und auf die Vorgehensweise bei einer gerichtlichen Strafverfolgung. Nur in $\$ 6$, der festlegte, daß bei Kenntnis von Zuwiderhandeln gegen das Gesetz eine Anzeigepflicht bestand, hieß es, daß die Strafverfolgung „auf Antrag des Amtes für Kontrolle des Warenverkehrs" erfolge. Dies schränkte die Rechte der Staatsanwaltschaft erheblich ein, die in Sachen nach dem Handelsschutzgesetz nicht von

168 Ebenda, S. 336.

169 Protokoll der Politbürositzung, 21. 3. 1950, SAPMO, DY 30 J IV 2/2/77, TOP 5; die Vorlage vom 20. 3. 1950 in: BAB, DO1/34.0 Nr. 5375.

170 Protokoll der Sekretariatssitzung, 17. 4. 1950, SAPMO, DY 30 J IV 2/3/101, TOP 1; die Vorlage mit Begründung vom 16. 4. 1950 in: BAB, DO1/34.0 Nr. 5375.

171 Protokoll der Politbürositzung, 18. 4. 1950, Auszug, in: DzD II/3, S. 682; Protokoll der Sitzung der Provisorischen Regierung, 20. 4. 1950, BAB, DC20 I/3 Nr. 16, Bl. 119; GBl. 1950, S. 327 f.

172 Zur Bestätigung von Ruh siehe das Protokoll der Sekretariatssitzung, 28. 4. 1950, SAPMO, DY 30 J IV 2/3/104, TOP 20. 
sich aus tätig werden durfte, sondern erst einen Antrag des AKW abwarten mußte; das AKW jedoch erhielt als justizfremde Instanz eine ungewöhnlich starke Stellung, da es von ihm abhing, ob ein Verfahren überhaupt eröffnet wurde ${ }^{173}$.

Erhebliche Schwierigkeiten beim Aufbau des AKW, dessen Kräfte weitgehend von der Volkspolizei stammten und für ihre Aufgabe erst ausgebildet werden mußten, veranlaßten die SKK Anfang Juni 1950 zu heftiger Kritik an der trotz starken Schmuggels mangelhaften Anwendung des Gesetzes ${ }^{174}$. Möglicherweise dadurch angestoßen, mußten die betroffenen DDR-Minister für Inneres, für innerdeutschen und Außenhandel, für Verkehr, Post und Justiz über die Durchführung des Gesetzes in der Regierungssitzung vom 7. September Bericht erstatten. Im Ergebnis der Sitzung wurde eine Kommission einberufen, die Vorschläge „zur Beseitigung der aufgetretenen Mängel und zur wirksameren Anwendung des Gesetzes" auszuarbeiten hatte ${ }^{175}$. Damit wurde das MdJ wieder stärker einbezogen, das in die Kommission Wolfgang Weiß als Vertreter entsandte; für die laufende Anwendung und Durchführung des Gesetzes bestimmte Staatssekretär GanterGilmans vom Ministerium für innerdeutschen und Außenhandel Heinrich Reuter von der Hauptabteilung $\mathrm{II}^{176}$. Zum 1. Oktober erhielt die juristische Abteilung des AKW zudem mit Kurt Flemming, einem Volksrichter aus Sachsen, einen Leiter ${ }^{177}$. All dies war erforderlich, um die Gerichtsverfahren nach dem Handelsschutzgesetz zu beschleunigen und mit dem „erforderliche[n] Nachdruck“"178 durchzuführen.

Im kleinen Kreis einigten sich Ruh, Weiß, Reuter und ein Vertreter der HVDVP am 15. September auf den bei den anstehenden Prozessen einzuhaltenden Verfahrensweg: Die Anträge auf Strafverfolgung waren vom AKW an die HVDVP zu richten, nach Abschluß der polizeilichen Ermittlungen hatte der zuständige Staatsanwalt binnen drei Tagen die Anklage zu erheben, und die Gerichtsverhandlung mußte innerhalb von drei Wochen durchgeführt werden. Eine Abschrift der Anklage und die Benachrichtigung über das Urteil waren umgehend an das MdJ zu senden ${ }^{179}$. Trotz der weiterhin ausschlaggebenden Rolle des AKW bei der Eröffnung des Verfahrens wurde durch die Regelung der Berichtspflichten dem Justizministerium damit eine weitgehende Steuerung der Prozesse ermöglicht. Das MdJ gab nun gemeinsam mit dem Generalstaatsanwalt eine Rundverfügung mit diesen Festlegungen heraus, die zusätzlich eine Anordnung enthielt, die strafverschärfend wirken sollte: Die Oberstaatsanwälte hatten „in allen Fällen, in denen das Urteil wesentlich unter den Anträgen der Staatsanwaltschaft liegt, oder aus

173 Siehe den Wortlaut des Gesetzes in: GBl. 1950, S. $327 \mathrm{f}$.

174 Besprechung Piecks, Grotewohls und Ulbrichts mit Tschujkow, Semjonow, Semitschastnow, Kowal, Bykow, Machalow am 8. 6. 1950, in: Badstübner/Loth, Pieck-Aufzeichnungen, S. $348 \mathrm{f}$,, hier 349. Über die Anfänge des AKW ist wenig bekannt: sehr knapp Suwalski, Entwicklung der Zollverwaltung, S. 578f., und der Abschnitt zur Arbeit des AKW im Protokoll der Unterredung mit Ruh im Frühjahr 1951, SAPMO, DY 30 IV 2/11/176, Bl. 397.

175 Protokoll der Sitzung der Provisorischen Regierung, 7. 9. 1950, BAB, DC20 I/3 Nr. 30, Bl. $3 \mathrm{f}$.

176 Vermerk von Weiß über die Besprechung am 11.9. 1950, Protokoll über die Sitzung am 11.9. 1950, BAB, DP1 VA Nr. 399.

177 Vgl. dazu MdI an MdJ, 21. 9. 1950, MdJ Sachsen an MdJ, 24. 10. 1950, BAB, DP1 SE Nr. 3474, Bl. $1030 \mathrm{f}$.

178 Vermerk von Weiß über die Besprechung am 11. 9. 1950, BAB, DP1 VA Nr. 399.

179 Aktenvermerk Ruhs, 15. 9. 1950, ebenda. 
sonstigen Gründen nicht aufrecht erhalten werden kann, Revision einzulegen" 180 . Das MdJ versuchte zudem, einzelne Prozesse durch mündliche Anweisungen vor Ort zu steuern. Zu diesem Zweck unternahm Reuter vom 10. bis zum 15. November gemeinsam mit Flemming und unter zeitweiliger Begleitung von Otto Grube eine Dienstreise nach Potsdam, Erfurt, Leipzig und Halle. Während in Potsdam die bei der dortigen Staatsanwaltschaft anhängigen Verfahren durchgesprochen wurden, fanden in Erfurt, Leipzig und Halle im Zusammenhang mit einem Gerichtsverfahren Besprechungen mit allen Wirtschaftsstaatsanwälten des jeweiligen Landes statt, in denen Reuter unter anderem dazu aufforderte, „bei der Strafzumessung von einem mittleren Strafmaß auszugehen", das bei etwa 10 Jahren Zuchthaus liege; je nach Schwere der Tat könne man dann nach oben und nach unten differenzieren. Reuter und Flemming scheuten sich auch nicht, einen widerstrebenden Richter am Landgericht Leipzig vor einem entsprechenden Verfahren „von der Bedeutung des Gesetzes mit seinen hohen Strafen zu überzeugen"181. Die Wirkung solcher Kampagnen blieb vorerst noch begrenzt. Ein Bericht über die Handhabung des Handelsschutzgesetzes hielt fest, daß zwar im ersten Halbjahr 1951 im Vergleich zu den vorangegangenen sechs Monaten die Zahl der Verfahren erheblich angestiegen sei; jedoch wurde beklagt, daß die Gerichte zu viele Verfahren einstellten und bei den Verurteilungen vielfach nur die gesetzlichen Mindeststrafen von drei Jahren Gefängnis bzw. fünf Jahren Zuchthaus verhängten ${ }^{182}$. Erst mit der Zeit und unter der verstärkten Einschaltung der Obersten Staatsanwaltschaft und des Obersten Gerichts änderte sich diese Strafpraxis ${ }^{183}$.

In den Verfahren nach dem Handelsschutzgesetz gelang es 1951 sogar, die Befugnisse des AKW zugunsten der Justiz einzuschränken. Dies ging freilich nicht auf eine Initiative des Justizministeriums, sondern auf eine sowjetische Anweisung zurück. Bei einem Besuch in Karlshorst Anfang Juli wurde Fechner gegenüber zum Ausdruck gebracht, „daß es unzweckmäßig sei, wenn das Amt zur Kontrolle des Warenverkehrs allein darüber entscheidet, welche Sachen es an die Gerichte abgebe. Es sei zu erstreben, daß das Amt zur Kontrolle des Warenverkehrs über die Abgabe gemeinsam mit der Staatsanwaltschaft entscheidet." 184 Mit dieser Maßgabe wurde ein Verordnungsentwurf ausgearbeitet, der am 16. Juli 1951 dem Sekretariat des ZK vorlag. Hinzugezogen zu diesem Tagesordnungspunkt wurden interessanterweise nicht nur Anton Ruh sowie die Leiter der Abteilungen für Wirtschaft und Staatliche Verwaltung, Ernst Scholz und Anton Plenikowski, sondern auch Justizminister Fechner und Hildegard Heinze von der Obersten Staatsanwaltschaft ${ }^{185}$. Das Sekretariat billigte den Entwurf, demzufolge Verstöße gegen das Handelsschutzgesetz entweder auf Antrag des AKW oder einer Dienststelle der Wirtschaftsverwaltung oder auch unmittelbar durch die

180 Rundverfügung Nr. 122/50, 21. 9. 1950, BAB, DP1 SE Nr. 1199; auch der Passus über die Staatsanwaltschaft ging auf die Besprechung am 15.9.1950 zurück.

181 Bericht Reuters, 16. 11. 1950, BAB, DP1 VA Nr. 399.

182 Analyse der Kriminalität der gerichtlichen Praxis in Sachen, die Verstöße gegen den innerdeutschen Handel zum Gegenstand haben, Bericht für die SKK vom 30.10. 1951, BAB, DP1 VA Nr. 376, Bl. 53-71, hier $56 \mathrm{f}$.

183 Siehe dazu Kap. B.VIII.5 und 6.

184 Notiz Nathans, 4. 7. 1951, BAB, DP1 VA Nr. 7192.

185 Protokoll der Sekretariatssitzung, 16. 7. 1951, SAPMO, DY 30 IV 2/3/215, TOP 1, Anlage Nr. 1. 
Staatsanwaltschaft verfolgt werden konnten; die am 26. Juli von der Regierung erlassene Verordnung weitete außerdem den Geltungsbereich des Handelsschutzgesetzes „auf den gesamten Warenverkehr zwischen dem Gebiet der Deutschen Demokratischen Republik und dem übrigen Deutschland“ aus ${ }^{186}$. Wie die gemeinsame Rundverfügung des $\mathrm{MdJ}$ und des Generalstaatsanwalts vom 15. August erläuterte, hatte von nun an nicht mehr das AKW, sondern die Staatsanwaltschaft "darüber zu entscheiden, ob eine gerichtliche Strafverfolgung erforderlich ist“. Bei geringfügigen Verstößen konnte die Polizei oder der Staatsanwalt die Sache auch an eine Stelle der Wirtschaftsverwaltung abgeben; sollte die Sache aber vor Gericht kommen, hatte der Staatsanwalt zu prüfen, „ob die Anklage nach dem Handelsschutzgesetz, nach der Wirtschaftsstrafverordnung, nach dem Gesetz zur Regelung des innerdeutschen Zahlungsverkehrs oder nach anderen gesetzlichen Bestimmungen zu erheben ist " ${ }^{187}$. Dem AKW verblieb somit neben Ordnungsstrafverfahren nur noch die Möglichkeit, die sogenannte „Schmuggelware“ einzuziehen ${ }^{188}$; für die Gerichtsverfahren wurde nun in einem umfassenden Sinne die Staatsanwaltschaft verantwortlich. Die Steuerung der Prozesse ging damit zwar vom MdJ auf die Oberste Staatsanwaltschaft über ${ }^{189}$; in unserem Zusammenhang ist jedoch entscheidend, daß eine justizfremde Instanz, die sich offensichtlich nicht bewährt hatte, mit sowjetischer Hilfe wieder aus der Strafverfolgung verdrängt wurde.

Bereits vor Verabschiedung des Handelsschutzgesetzes hatte in Verfahren nach der Wirtschaftsstrafverordnung die Wirtschaftsverwaltung ein ähnlich weitgehendes Recht wie das AKW erhalten. Die Wirtschaftsstrafverordnung vom 23. September $1948^{190}$, die weitgehend in der DWK erarbeitet worden war - die DJV hatte sich mit wesentlichen Forderungen nicht durchsetzen können ${ }^{191}$-, sah sowohl Verwaltungsverfahren als auch Gerichtsverfahren vor: Die Entscheidung darüber, welches Verfahren zu wählen war, lag indes nicht bei der Justiz, sondern beim zuständigen Minister oder seinem Beauftragten - meistens beim Landrat oder beim Bürgermeister. Er mußte Verlangen auf gerichtliche Strafverfolgung stellen, wenn nach seinem Ermessen eine Haftstrafe oder Geldstrafe von mehr als

186 Verordnung zum Schutze des innerdeutschen Warenverkehrs, 26. 7. 1951, in: GBl. 1951, S. 705 f. 187 Rundverfügung Nr. 115/51, 15. 8. 1951, BAB, DP1 VA Nr. 6284, Bl. 140.

188 Die Rundverfügung vom 15.8. 1951 legte in diesem Zusammenhang fest: „Die Verhängung einer Ordnungsstrafe steht der Durchführung eines gerichtlichen Verfahrens wegen derselben Zuwiderhandlung nicht entgegen. "Dies verstieß, wie das thüringische Justizministerium in einem Schreiben an das MdJ vom 16.11.1951 feststellte, gegen den Grundsatz "ne bis in idem“; diese Einwände wurden von Rudolf Reinartz aber mit dem Hinweis beiseite gewischt, daß der Grundsatz nur dort gelte, "wo das Gesetz etwas Abweichendes nicht vorschreibt“" siehe BAB, DP1 VA Nr. 7192. Vgl. dazu auch Kap. B.IV.3 und Wentker, Volksrichter, Dok. 35, S. 218.

189 Siehe Kap. B.VII.6.

190 Verordnung über die Bestrafung von Verstößen gegen die Wirtschaftsordnung (Wirtschaftsstrafverordnung) in: ZVOBl. 1948, S. 439-443.

191 Dies bezog sich vor allem auf den weit auslegbaren $\$ 1$ der Verordnung. Die DJV wollte, wie ihr Vertreter Weiß darlegte, $\ 1$ dadurch relativieren, daß in der Verordnung zunächst konkrete strafbare Tatbestände, die den „Normalfall“ bilden sollten, benannt und eine Blankettbestimmung lediglich als „Ergänzung" angeschlossen wurde: siehe Stenographische Niederschrift des Ausschusses für Rechtsfragen beim Zentralsekretariat der SED, 3./4 1. 1948, SAPMO, DY 30 IV 2/1.01/70, Bl. 57-59; Chef der DJV an DWK, 10. 2. 1948, BAB, DP1 VA Nr. 7243. Zur Entstehung der Wirtschaftsstrafverordnung eingehend Braun, ZKK (Diss.). 
100000 DM oder eine Vermögenseinziehung erforderlich schien ${ }^{192}$. Damit wurden gleichzeitig den Gerichten die Mindeststrafen vorgeschrieben, die sie in Prozessen nach der Wirtschaftsstrafverordnung zu verhängen hatten.

Interessanterweise hatte trotz dieser Kompetenzeinbuße die DJV vorerst nicht das Bedürfnis, sich verstärkt in diese Verfahren einzuschalten: Im Gegenteil, auf einen entsprechenden Vorstoß des DWK-Vorsitzenden vom Juli 1949 antwortete Fechner im September, „daß es sich im gegenwärtigen Zeitpunkt noch nicht empfiehlt, die Bearbeitung aller Wirtschaftsstrafsachen wieder ausschließlich der Justiz zu übertragen“, da diese dann mit zu vielen geringfügigen Wirtschaftsdelikten belastet würde. Er empfahl jedoch, „der Staatsanwaltschaft die Entscheidung darüber zu übertragen, ob ein Verfahren von den Gerichten oder von den Wirtschaftsbehörden durchgeführt wird“ ${ }^{193}$. Dieser Vorschlag wurde nicht umgesetzt, und die Verantwortlichen in der Justiz scheuten sich auch weiterhin, an der Frage zu rühren. Dies ging so weit, daß das Justizministerium eine für notwendig erachtete Durchführungsverordnung zur Wirtschaftsstrafverordnung immer wieder aufschob, „weil man glaubte, daß man in ihr die Frage, zumindest teilweise, der Rückübertragung aller Strafsachen an die Justiz mitregeln würde“"194. Insgesamt überwog bei den Justizbehörden offensichtlich die Befriedigung darüber, von Bagatellfällen beim Wirtschaftsstrafrecht entlastet worden zu sein, gegenüber dem Bedürfnis, übergeordnete Entscheidungskompetenzen zu bewahren, zumal sie keine größere Veranlassung sahen, die Tätigkeit der Verwaltungsorgane bei der Anwendung der Wirtschaftsstrafverordnung zu monieren ${ }^{195}$.

Die Instrumentalisierung der Justiz durch die Wirtschaftspolitik seit 1948 verfolgte vor allem zwei Ziele: harte Bestrafung jeglicher Aktivitäten, die in irgendeiner Weise als Plangefährdung angesehen werden konnten, und die Einziehung von Privateigentum als beabsichtigte Folge entsprechender Strafprozesse. Als gesetzliche Grundlage diente vor allem die Wirtschaftsstrafverordnung mit ihrem weit gefaßten $\$ 1$, einer Blankettbestimmung, die jegliche Gefährdung des Wirtschaftsplans unter Strafe stellte. Die politische Instrumentalisierung der Wirtschaftsstrafjustiz führte - wie bei den Verfahren nach Befehl Nr. 201 - zu einer Reduzierung der Rolle der Justiz und zu deren Anpassung an die politischen Erfordernisse. Dies implizierte die Bildung spezieller Wirtschaftsstrafkammern, deren Personal einer besonderen Auswahl unterlag. Während bei Befehl Nr. 201 die Bildung solcher Kammern durch die sowjetische Militärverwaltung angeordnet worden und lediglich deren Besetzung Gegenstand mündlicher Anweisung war, wurde die Konstituierung der Wirtschaftsstrafkammern von Anfang an konsequent verschleiert.

Ausgangspunkt der justizinternen Diskussion bildete eine Anregung der Juristenkonferenz in Dresden vom Juli 1948, Spezialgerichte für Wirtschaftsstrafsachen zu bilden. Sie wurde von der DJV aufgegriffen und dahingehend modifiziert

192 Vgl. $\$ 21$ der Wirtschaftsstrafverordnung.

193 Chef der DJV an den Vorsitzenden der DWK, 1. 9. 1949, BAB, DP1 VA Nr. 322.

194 Vermerk von Weiß, 22. 5. 1950, ebenda. Die 2. Durchführungsverordnung wurde dann erst am 17. 5. 1951 erlassen: siehe GBl. 1951, S. $481 \mathrm{f}$.

195 Analyse der Kriminalität, der gerichtlichen Praxis und der entsprechenden Verwaltungsorgane bei der Anwendung der Wirtschaftsstrafverordnung, Bericht an die SKK, 10. 11. 1951, BAB, DP1 VA Nr. 376, Bl. 287-328, hier 310-314. 
und präzisiert, daß „bei den Landgerichten besondere Wirtschaftsstrafkammern einzurichten" waren. Am 21. Dezember 1948 rückten Hilde Benjamin, Heinze, Wolfgang Weiß und Berger von der SED-Justizabteilung davon wieder ab, da „die Einrichung solcher Wirtschaftsstrafkammern den Eindruck erwecken könnte, als sollte wieder eine Art von ,Sondergerichten' geschaffen werden" ${ }^{196}$. Deshalb einigten sie sich darauf, eine Verordnung über die Zuständigkeit in Wirtschaftsstrafsachen zu erlassen, in der grundsätzlich die großen Strafkammern der Landgerichte für zuständig erklärt wurden, um auf diese Weise für härtere Urteile zu sorgen und die Rechtsprechung zu vereinheitlichen ${ }^{197}$. Die großen Strafkammern sollten mit jeweils zwei Richtern und drei Schöffen besetzt werden. Dies bedeutete zwar eine Abweichung vom Gerichtsverfassungsgesetz, das drei Richter und zwei Schöffen vorschrieb, wurde aber mit der bestehenden Richterknappheit, einer entsprechenden Praxis in Thüringen und den Planungen in Sachsen und Sachsen-Anhalt sowie unter Verweis auf die 201-Kammern begründet ${ }^{198}$. Schließlich und darin lag die entscheidende Einflußmöglichkeit der Justizverwaltung - war „durch interne Dienstanweisung“ sicherzustellen, „daß die für die Verhandlung und Entscheidung von Wirtschaftsstrafsachen zuständigen Kammern mit solchen Richtern besetzt werden, die hierfür besonders qualifiziert sind“. Auch die Einsetzung von besonderen Wirtschaftsstaatsanwälten, „die man nicht unbedingt so nennen muß “, sollte aufgrund einer internen Dienstanweisung erfolgen ${ }^{199}$. DJV und SED-Justizabteilung strebten sehr wohl die Errichtung von Wirtschaftsstrafkammern an, sie sollten nur nicht als solche erkennbar sein.

Nachdem die Verordnungsentwürfe von Weiß zunächst DJV-intern gebilligt worden waren, wurden sie am 15. März 1949 mit den skizzierten Begründungen an die SMAD-Rechtsabteilung weitergeleitet. Das Begleitschreiben verdeutlichte, daß die Bestellung der Richter und Staatsanwälte für die Wirtschaftsstrafkammern nicht allein den Landesjustizministerien überlassen werden, sondern „im Einvernehmen mit der DJV“ erfolgen sollte, um nicht nur deren fachliche Qualität, sondern auch deren politische Loyalität sicherzustellen 200. Die SMAD-Rechtsabteilung erteilte der DJV am 9. August ihr Einverständnis ${ }^{201}$, so daß beide Verordnungen, wie ursprünglich geplant, nach ihrem Erlaß am 8. und 11. August 1949 mit ihrer Verkündung am 1. September gemeinsam in Kraft treten konnten ${ }^{202}$. Vier Tage später erging dann auch die interne Dienstanweisung in Form einer Rund-

196 Begründung von Weiß zum Entwurf der Verordnung über die Zuständigkeit in Wirtschaftsstrafsachen, BAB, DP1 VA Nr. 7181.

197 Die Staatsanwalt konnte dem Entwurf zufolge zwar die Zuständigkeit der Amtsgerichte in solchen Strafsachen grundsätzlich begründen, aber nur dann, wenn keine Strafe über drei Jahren Zuchthaus zu erwarten war. Ziel war es somit, „mehr Wirtschaftsstrafsachen als bisher vor die Landgerichte " zu bringen und damit härtere Strafen zu verhängen. Außerdem sollten die speziellen Wirtschaftsstrafkammern der Landgerichte als Berufungsinstanz für die Urteile der Amtsgerichte fungieren: siehe Entwurf: Zuständigkeit in Wirtschaftsstrafsachen, ebenda.

198 Begründung von Weiß zum Entwurf der Verordnung über die Besetzung in Strafkammern, ebenda.

199 Vermerk von Weiß über Besprechung am 21. 12. 1948, BAB, DP1 SE Nr. 377.

200 Chef der DJV an SMAD-Rechtsabteilung, 15. 3. 1949, BAB, DP1 VA Nr. 7181.

201 Ursprünglich wollte auch die SMAD-Rechtsabteilung Einfluß auf die Besetzung der Wirtschaftsstrafkammern geben, verzichtete aber letztlich darauf: siehe Vermerke von Weiß über Unterredungen mit Korobow am 25.7. und 9. 8. 1949, ebenda.

202 Siehe ZVOBl. 1949, S. 614, 618. 
verfügung der DJV, in der nicht nur die Zielsetzung der beiden Verordnungen erläutert, sondern auch die Besetzung der Richter- und Staatsanwaltsstellen angesprochen wurde. Fechner empfahl, auf die Teilnehmer der zu Beginn des Jahres durchgeführten Speziallehrgänge zurückzugreifen, und forderte dazu auf, die Landgerichte zu benennen, an denen Spezialkammern für Wirtschaftsstrafsachen vorgesehen seien, und die Personalvorschläge mitzuteilen ${ }^{203}$. Alle Justizministerien außer das mecklenburgische, das Personalknappheit geltend machte, übersandten die erforderlichen Unterlagen nach Berlin ${ }^{204}$, so daß am 21. Oktober eine Arbeitsbesprechung über diese Fragen im MdJ stattfinden konnte. Die Personalvorschläge wurden noch nicht endgültig abgesegnet; Benjamin machte zudem darauf aufmerksam, daß Richter und Staatsanwälte mit praktischer Erfahrung, nicht aber frisch ausgebildete Volksrichter einzusetzen waren. Schließlich kündigte Hartwig weitere Sonderkurse auf dem Gebiet des Wirtschaftsstrafrechts $a^{205}$. Anfang 1950 schließlich nahmen die Wirtschaftsstrafkammern ihre Tätigkeit auf, ohne daß sie offiziell so bezeichnet wurden. Bis Ende 1950 sprach man justizintern nur von „sogenannten Wirtschaftsstrafkammern“; aber auch dieser sprachliche Vorbehalt war ab Anfang 1951 nicht mehr erforderlich, da das MdJ am 26. Januar anordnete, diese nur noch als „2. Strafkammer“ zu bezeichnen ${ }^{206}$.

Auf bedeutende Prozesse vor diesen Kammern sollte ein mit dem MfS in mehrfacher Hinsicht vergleichbares Untersuchungsorgan erheblichen Einfluß gewinnen: die Zentrale Kontrollkommission bzw. die Landeskontrollkommissionen. Spätestens seit Januar 1948 von Ulbricht und der DWK nach dem Vorbild der sowjetischen „Rabkrin“ (Kommissariat der Arbeiter- und Bauerninspektion) geplant ${ }^{207}$, wurde ihre Bildung am 29. Mai 1948 offiziell von der Deutschen Wirtschaftskommission beschlossen. Unter der Leitung des Altkommunisten Fritz Lange bestand die ZKK aus neun Personen; in den Ländern unterstanden ihr jeweils fünfköpfige Landeskontrollkommissionen, die sich wiederum auf Kreiskontrollbeauftragte und die seit 1945/46 bestehenden ehrenamtlichen Volkskontrollausschüsse stützten. Die Kontrollkommission setzten sich durchgehend aus SED-loyalen Kadern zusammen. Ihre Hauptaufgaben bestanden in der Überwachung der Einhaltung der Wirtschaftspläne, der Bekämpfung des Schwarzmarkts sowie von Kompensationsgeschäften und der Beseitigung von bürokratischen Hindernissen in der Verwaltung. Für die Justiz erhielt sie deshalb eine so große Bedeutung, weil sie als Untersuchungsorgan in Wirtschaftsstrafsachen fungieren konnte. De jure ein Organ der DWK, war sie de facto aufgrund der engen Beziehungen Ulbrichts zu Lange dem starken Mann in der SED-Führung unterstellt,

${ }^{203}$ DJV an Landesregierungen/Justizministerium, 5. 9. 1949, BAB, DP1 VA Nr. 7181. Zu den Speziallehrgängen siehe Kap. B.IV.3.

204 Siehe die Schreiben aus Mecklenburg vom 15.9., aus Sachsen vom 16. 9., aus Brandenburg und Sachsen-Anhalt vom 20.9. und aus Thüringen vom 3. 10. 1949, ebenda.

205 Protokoll über die Arbeitsbesprechung vom 21.10. 1949 im Ministerium der Justiz in Berlin, 24. 10. 1949, ebenda.

206 Rundverfügung Nr. 8/51, 26. 1. 1951, BAB, DP1 VA Nr. 6284, Bl. 14.

207 Zur Frühgeschichte der 1920 formell gegründeten Rabkrin siehe Perrins, Rabkrin and Workers' Control; in der sowjetischen Vorkriegsjustiz trat sie eher als Kontrollorgan und nicht so sehr als Untersuchungsorgan auf: siehe Solomon, Soviet Criminal Justice, S. 50-54, 107-109. 
die somit ein extralegales Instrument zur Durchsetzung ihrer Politik in der Justiz besaß208.

Die Kompetenzen der ZKK wurden auf der Staatspolitischen Konferenz der SED in Werder am 23./24. Juli 1948 festgelegt. Lange, der über die „Funktionen der Kontrollkommissionen und der Volkskontrollorgane" referierte, verkündete dort großspurig: „Die Kontrollkommissionen sind im Grunde genommen für alles kompetent; es dürfte also kaum Kompetenzstreitigkeiten geben."209 Darin freilich täuschte er sich. Benjamin wehrte sich zum einen gegen die Verpflichtung der Justiz, den Kontrollkommissionen „wirtschaftsschädigende Vorgänge mitzuteilen [und] auf Anforderung die zur Untersuchung notwendigen Unterlagen zugänglich zu machen", und zum anderen gegen das Recht der Kontrollkommissionen, „die Polizei bzw. die Justiz verpflichtend zu beauftragen, Personen festnehmen und Sachen sicherstellen zu lassen“. Obgleich Benjamin alles andere als eine Vertreterin einer unabhängigen Justiz war, wollte sie keine automatische Unterordnung der Justizbehörden unter die Kontrollkommission: Denn „die Justiz“, so Benjamin, „ist eine Staatsfunktion, die von selbständigen Justizorganen ausgeübt wird, genauso wie die DWK ein selbständiges Organ ist". Während sie durchaus den Führungsanspruch der Partei im Justizwesen akzeptierte und bereit war, die Justiz nach deren Bedürfnissen umzustrukturieren, lehnte sie eine Zwischeninstanz zwischen SED und Justizbehörden in Form der ZKK ab. Vereinbarungen, wie sie ihr vorschwebten, mußten zwischen der DWK und der DJV als gleichberechtigten Zentralverwaltungen bzw. zwischen den LKK und den Generalstaatsanwälten der Länder abgeschlossen werden und die Justizbehörden auf bestimmten, klar umgrenzten Gebieten zur Kooperation verpflichten. Interessanterweise betonte sie: „Die Justiz hat heute noch einen selbständigen Apparat. Ich kann mir durchaus eine politische Situation vorstellen, wo man den Justizapparat zeitweilig beiseitestellen wird. " Dabei konnte sie nur eine im klassischen Sinne revolutionäre Situation meinen, die nach Auffassung der SED-Führung jedoch nicht bestand. Die Kontrollkommissionen in der damaligen Form würden jedoch die Gerichte zu „Jasager[n]“ degradieren. Ulbricht widersetzte sich Benjamin mit den Worten: „Du sprichst, als ob Deine Richter und Justizangestellten demokratisch wären.“ Nach seiner Auffassung waren die Kontrollkommissionen als Mittlerinstanzen des Parteiwillens für die Justiz unabdingbar, solange an Gerichten und Staatsanwaltschaften noch Justizjuristen „alter Schule“ dominierten. Zwar gab er vor, daß eine generelle Kontrolle der Justiz durch die Kontrollkommissionen nicht beabsichtigt sei, daß die SED sich „genau an den Buchstaben des Gesetzes der Landesverfassungen " halten und die Unabhängigkeit der Justiz in keiner Weise verletzt werde; die Vorschläge Benjamins wies er jedoch ebenso zurück wie einen Vorstoß Schäfermeyers, Justizvertreter sowohl in die ZKK als auch in die Landeskommissionen aufzunehmen ${ }^{210}$. Die Richtlinien für die Kontrollkommissionen wurden

208 Vgl. dazu vor allem Braun, Zentrale Kommission für Staatliche Kontrolle, S. 6f.; Zank, Wirtschaftliche Zentralverwaltungen, S. 269 f. Die Anordnung über die Bildung von Kontrollkommissionen bei der DWK und in den Ländern der SBZ in: ZVOBl. 1948, S. 240.

${ }^{209}$ Zit. nach: Die neuen Aufgaben, S. 84.

210 Stenographisches Protokoll der Konferenz von Werder, 23./24. 7. 1948, SAPMO, DY 30 IV 2/13/ 110, Bl. 228-234, teilweise zit. bei Braun, Zentrale Kommission für Staatliche Kontrolle, S. $18 \mathrm{f}$. 
daher in Werder unverändert verabschiedet und von der DWK am 8. September übernommen ${ }^{211}$. Die DJV wiederum erließ im Zusammenhang mit den Richtlinien eine erläuternde Rundverfügung, in der sie genauer auf die Pflichten der Justizorgane einging: Diese seien erstens verpflichtet, „jedem Ersuchen der Kontrollkommissionen mit besonderer Beschleunigung nachzukommen", könnten zweitens den obligatorischen Auftrag erhalten, „Personen festzunehmen und Sachen sicherstellen zu lassen“, und drittens könnten „die Staatsanwaltschaften über den Generalstaatsanwalt - von den Kontrollkomissionen zur Anstellung von Ermittlungen und zur Anklageerhebung angewiesen werden" 212 .

Die Weitergabe der ZKK-Richtlinien war nicht nur auf die auch für die DJVSpitze geltende Parteidisziplin zurückzuführen, sondern auch auf den ersten "Testfall“ der ZKK, dem von ihr initiierten und inszenierten Schauprozeß gegen angebliche Textilschieber in Glauchau-Meerane. Unmittelbar nach der Konferenz von Werder, Ende Juli 1948, begann die ZKK in der sächsischen Kleinstadt Meerane mit einer mehrwöchigen Verhaftungsaktion, an deren Ende über dreißig Textilunternehmer im Gefängnis saßen. Der in der Nachkriegszeit übliche, von deutschen und sowjetischen Stellen nicht nur geduldete, sondern sogar mitgetragene Tauschhandel zur Aufrechterhaltung der Produktion wurde zum Anlaß genommen, um den Verhafteten Wirtschaftsverbrechen größten Ausmaßes vorzuwerfen. Obgleich das Statut der ZKK noch nicht verabschiedet war, gebärdeten sich deren Repräsentanten bereits als Vorgesetzte des Justizapparats: Sie wiesen die Glauchauer Amtsanwälte an, die Festgenommenen in Einzelhaft unterzubringen und ihnen keine Sprecherlaubnis zu gewähren, sie entschieden, welche Personen anzuklagen waren, daß die Verfahren vor der großen Strafkammer des Landgerichts Zwickau „in einem großen Schauprozeß“ durchgeführt werden sollten, gaben Anweisungen zum Einsatz eines „besonders tüchtigen, energischen und einwandfreien Staatsanwalt[s]" sowie zur Besetzung der Strafkammer und kontrollierten die Anklageschrift ${ }^{213}$. Noch vor Abschluß der Ermittlungen, am 15. September, veröffentlichte das „Neue Deutschland“ einen formell an die DWK und die DVdI gerichteten „Amtlichen Bericht [...] über die Verhältnisse in der Textilindustrie in Glauchau-Meerane“, der der SED-Führung als sinnfälliger Beleg für die „Verschärfung des Klassenkampfes" durch die Kapitalisten galt. Wie Ulbricht am selben Tag vor dem SED-Parteivorstand betonte, wurden darin auch Vorwürfe gegen die Justiz in Glauchau-Meerane erhoben, die in Zusammenarbeit mit den dortigen Unternehmern Bestrafungen verhindert hätte. Die versuchten Behinderungen des neuen Untersuchungsorgans durch einzelne Justizangehörige ließen Ulbricht nochmals die außergewöhnlichen Rechte der ZKK betonen: „Ich möchte hier den Parteivorstandsmitgliedern sagen, daß von Angestellten in der Justiz und in Staatsorganen in Sachsen versucht wurde, während der Untersuchung einzugreifen, und daß wir den Genossen in den Kontrollkommissionen gesagt haben,

${ }^{211}$ Abdruck der Richtlinien in: Die neuen Aufgaben, S. 91-94. Die vom DWK-Sekretariat am 8. 9. 1948 verabschiedeten und am 13. 9. 1948 der DJV übermittelten Richtlinien sind damit textidentisch: siehe BAB, DP1 VA Nr. 315, Bl. 16-18, gedruckt in: Unrecht als System I, S. $77 \mathrm{f}$.

212 Chef der DJV an Landesregierungen/Justizministerium, 22.9. 1948, BAB, DP1 VA Nr. 315, Bl. 28, teilweise gedruckt in: Unrecht als System I, S. 76 f.

${ }_{213}$ Siehe dazu Klawitter, Rolle der ZKK, S. 27-31, Zitate S. 30 f. 
daß kein Minister, kein Generalstaatsanwalt und niemand sich einmischen darf. Die Kontrollkommission ist eine selbständige Instanz, sie hat keinem anderen zu berichten als dem Sekretariat der Deutschen Wirtschaftskommission, und zwar nach Abschluß der Untersuchungen. Bis dahin hat kein Minister, hat kein Staatsfunktionär und kein Staatsanwalt hineinzureden und zu versuchen, eventuell die Verhaftung von Leuten zu verhindern oder ihre Freilassung zu erreichen."214

Nachdem durch den "Amtlichen Bericht" und durch Ulbricht die Justiz in Glauchau-Meerane diskreditiert worden war, blieb der DJV nichts anderes übrig, als klein beizugeben. Sie stellte fest, daß der ZKK-Bericht „auch eine Anklage gegen einzelne Organe der Justiz" darstelle, und setzte einen aus DJV-Angehörigen und der sächsischen Generalstaatsanwaltschaft bestehenden Untersuchungsausschuß zur Überprüfung der Amtsanwaltschaft beim Amtsgericht Glauchau sowie der Strafkammer des Landgerichts Zwickau ein. Zudem bildete der „Fall Glauchau-Meerane" für sie den Anlaß, ihre eigene Kontrollabteilung zu verstärken und den Landesjustizministerien eine Reihe von Anweisungen zukommen zu lassen. Auch diese sollten ihre Kontrollabteilungen „aktivieren“, mehr Volksrichter einstellen und befördern, Rechtsanwälte verstärkt auf ihre NS-Belastung überprüfen, die Tätigkeit der Kontrollkommissionen ,in jeder Weise“ unterstützen und die Bekämpfung von Wirtschaftsverbrechen beschleunigen und verschärfen: Die Richter und Staatsanwälte waren anzuhalten, Wirtschaftsverbrecher nicht mehr gegen Sicherheitsleistung oder wegen Haftunfähigkeit zu entlassen und härtere Strafen zu verhängen, bei denen „die Sicherung der Wirtschaftspläne [...] die ihr gebührende Berücksichtigung finden muß"215. Das angebliche Versagen der Justiz in Glauchau-Meerane beförderte nicht nur die Bereitschaft der DJV-Spitze, die Unterordnung der Justiz unter die ZKK hinzunehmen, sondern veranlaßte diese auch zu einer intensivierten Justizsteuerung und strafverschärfenden Anweisungen, um künftiger Kritik und möglichen weiteren Kompetenzeinbußen zu begegnen.

Die ZKK blieb auch nach der DDR-Gründung bestehen. Umbenannt in Zentrale Kommission für staatliche Kontrolle, wurde sie formell dem Ministerpräsidenten unterstellt; de facto war sie auch weiterhin das extralegale Organ der SEDFührung zur Durchführung der „Revolution von oben“ in Wirtschaft und Gesellschaft ${ }^{216}$. Die von ihr initiierten und gesteuerten Wirtschaftsstrafprozesse zielten eindeutig auf Enteignung, um anschließend Betriebe und Vermögen in Volksei-

214 Protokoll der Parteivorstandstagung, 15. 9. 1948, in: Friedrich u.a., Entscheidungen der SED, S. 325 f. (das Zitat S. 326). Bereits am 12.9. 1948 hatte die Ost-CDU-Zeitung "Neue Zeit" in dem Artikel „Das unkontrollierte Kontrollsystem" die Vollmachten der keiner parlamentarischen Instanz unterworfenen ZKK kritisiert und dabei deren „überraschend weitgehende Weisungsbefugnisse gegenüber den öffentlichen Exekutivorganene und der Rechtsprechung " betont, „die auf eine direkte Beschneidung der Justizhoheit hinauslaufen": siehe BAB, DP1 VA Nr. 315, B1. 64. Zum Ausgang des Prozesses siehe Klawitter, Rolle der ZKK, S. 35-37.

215 Siehe Verlautbarung der DJV zum Fall Glauchau-Meerane, o.D., BAB, DP1 VA Nr. 5575. Die Verlautbarung erschien am 1. 10. 1948 im „Neuen Deutschland“ unter dem Titel: „Wirtschaftsverbrecher scharf bestrafen! Eine Verlautbarung der Justizverwaltung ". Siehe dazu auch: DJV an SMAD-Rechtsabteilung, 29. 9. 1948, BAB, DP1 VA Nr. 7825; Chef der DJV an Landesregierungen/Justizministerium, 25. 9. 1948, BAB, DP1 VA Nr. 315, Bl. $39 \mathrm{f}$.

216 Vgl. Bekanntmachung über den Strukturplan der Provisorischen Regierung der DDR, 1.11. 1949, in: GBl. 1949, S. 2; vgl. auch Klawitter, Rolle der ZKK, S. 38, Anm. 44. An der Abkürzung ZKK wird im folgenden festgehalten. 
gentum überführen zu können217. Von einer Verlagerung des Aufgabenschwerpunkts der ZKK nach der Staatsgründung kann daher keine Rede sein ${ }^{218}$. Denn die ZKK hielt nicht nur an ihren schriftlich niedergelegten Kompetenzen, sondern auch an ihrer seit den Vorgängen von Glauchau-Meerane gängigen Praxis fest, die eine ständige Überschreitung dieser Zuständigkeiten implizierte. Der „juristische Beirat" der ZKK, Max Masius ${ }^{219}$, verdeutlichte auf einer groß angelegten Arbeitstagung Ende Januar 1950, daß die Arbeit der Kontrollkommissionen nicht mit der Übergabe des Untersuchungsberichts an die Staatsanwaltschaft ende. „Oberste Richtlinie" sei vielmehr, "wichtige Prozesse von ihrem Anfang bis zum Ende, d.h. durch alle Instanzen hindurch bis zur Rechtskraft des Urteils, ja gegebenenfalls bis zur Vollstreckung [zu] beobachten“. Eine solche Prozeßüberwachung schloß, wie Masius darlegte, vor allem persönliche Kontaktaufnahmen mit den zuständigen Staatsanwälten und Richtern ein, die auf die Bedeutung des Falles ebenso wie auf die besondere Rolle des Volkseigentums in der DDR hinzuweisen waren. All dies habe „nichts, aber auch gar nichts mit irgendeiner Beeinflussung oder gar Unterdrückung von Staatsanwaltschaft und Gericht zu tun“, und es sei „selbstverständlich nicht unsere Aufgabe, Gerichte zu schaffen oder die Art der Zusammensetzung der Gerichte zu forcieren“. Der anwesende Justizminister räumte die auf der Tagung ebenfalls geübte Kritik an der Justiz ein, versprach, die Tätigkeit der Kontrollkommissionen in seinem Arbeitsbereich zu popularisieren, signalisierte die Unterwerfung der Justiz unter den überlegenen Sachverstand der Kontrollkommissionen und erlaubte sich lediglich gegenüber den Beanstandungen Fritz Langes am Strafvollzug einige relativierende Bemerkungen ${ }^{220}$.

Welche Rolle die ZKK in bedeutenden Wirtschaftsstrafverfahren zu spielen vermochte, kann exemplarisch an dem Dessauer Schauprozeß gegen die Deutsche-Continental-Gas-Gesellschaft (DCGG) vom April 1950 gezeigt werden 221. Diese blieb trotz ihrer formellen Enteignung im September 1946 unter dem Dach der Provinzialsächsischen Energieversorgungs AG (Prevag) weiter bestehen und hatte mit Zustimmung der Provinzialregierung von Sachsen-Anhalt im Juni 1947 völlig legal eine Parallelfirma in Hagen/Westfalen gegründet, um ihr in den Westzonen gelegenes Betriebsvermögen nicht zu verlieren. Das wurde ihr und einigen prominenten Mitgliedern der Landesregierung in Halle, insbesondere Willi Brundert und Leo Herwegen, zum Verhängnis. Die ZKK ermittelte in dem Fall seit Ende 1948/Anfang 1949 und stellte im November in einem „amtlichen Bericht" Verschiebungen von Vermögen im Wert von fast 100 Millionen DM in den Westen fest. In Abstimmung zwischen Ulbricht und Lange erfolgte auch hier die Vorbereitung eines Prozesses. Nachdem der Generalstaatsanwalt des Landes, Werner Fischl, das ihm von der ZKK übergebene Material als unvollständig und die Angaben über das DCGG-Vermögen als ungenau bezeichnet hatte, wurde ihm kurzerhand im Dezember 1949 das Verfahren entzogen. Das Politbüro entschied am

217 Vgl. Braun, Zentrale Kommission für Staatliche Kontrolle, S. 13.

218 So aber Kos, Politische Justiz, S. 400, in Anlehnung an eine DDR-Publikation von 1977.

${ }_{219}$ Zur Person siehe Pohl, Justiz in Brandenburg (Manuskript), S. 131.

220 Protokoll der 3. Arbeitskonferenz der ZKK in: Staatliche Kontrolle - Volkskontrolle, hier S. 112118 (Masius), 136-139 (Fechner).

221 Siehe dazu jüngst Klawitter, Rolle der ZKK, S. 37-55; Kos, Politische Justiz. 
28. Februar 1950, das Verfahren dem Generalstaatsanwalt der DDR zu übergeben und vor dem ersten Senat des Obersten Gerichts zu inszenieren ${ }^{222}$. Es sanktionierte damit freilich nur eine zu Jahresbeginn wahrscheinlich zwischen Ulbricht und Lange getroffene Vereinbarung. Im Auftrag des Politbüros führten Lange und seine Mitarbeiter auch weiterhin die Regie in dem im Landestheater Dessau vom 26. bis 29. April 1950 stattfindenden Schauprozeß. Ihre Tätigkeit umfaßte Verhaftungen, Ermittlungen, Korrekturen der Anklageschrift und die Inszenierung der Aufführung. Das Gerichtsverfahren wurde von Lange und seinem Stellvertreter Anton Ruh von einem Logenplatz aus verfolgt und teils „durch einen organisierten Zetteldienst" 223 während der Verhandlung, teils durch die vier bis fünf täglichen Besprechungen zwischen ZKK, Gericht und Generalstaatsanwalt in den Pausen gelenkt.

Die für die ZKK typischen Kompetenzüberschreitungen waren nicht nur im Dessauer Prozeß, sondern in allen Verfahren festzustellen, in denen die Kontrollkommissionen als Untersuchungsorgan fungierten ${ }^{224}$. Bei den vereinzelten anfänglichen Auseinandersetzungen zwischen Kontrollkommissionen und Gerichten saßen erstere aufgrund ihrer Parteinähe am längeren Hebel. Die Justizverwaltung unterstützte auch in diesen Verfahren die Kontrollkommissionen in ihren zentralen Anliegen, so etwa die brandenburgische Hauptabteilung Justiz, als sie im Januar 1951 die Praxis kritisierte, auf Veranlassung der Kontrollkommissionen festgenommene Personen ohne Rücksprache mit diesen freizulassen ${ }^{225}$. Die ZKK wiederum registrierte auf seiten der Justiz nichts als Versagen angesichts der wirtschaftlichen und gesellschaftlichen Umgestaltung. In einem Bericht Langes für Ulbricht vom Juni 1951 bescheinigte sie der Justiz, daß sie „ihre Aufgaben im demokratischen Staat nicht erfüllt hat". Zahlreiche Fallbeispiele aus den Ländern untermauerten diese Kritik. Angesichts der ,Mängel' hatten sich die Kontrollkommissionen zu massiven Eingriffen veranlaßt gesehen, die weit über das hinausgingen, was Masius im Januar 1950 empfohlen hatte: So wies die ZKK in ihrem Bericht darauf hin, daß „in fast allen bedeutsamen Prozessen, soweit diese nicht vom Obersten Gericht durchgeführt wurden, sowohl Richter als auch Staatsanwälte im Rahmen der gesetzlichen Vorschriften von der Zentralen Kommission für Staatliche Kontrolle selbst vorgeschlagen und überprüft werden mußten, weil die oberen Justizbehörden in den Ländern in vielen Fällen dazu weder gewillt noch befähigt waren“226. Vor allem durch derartige Maßnahmen wurde jedoch bis 1952/1953, parallel zur Verdrängung der ZKK als Ermittlungsorgan in Wirt-

222 Die Darlegungen von Klawitter, Rolle der ZKK, S. 42, und Kos, Politische Justiz, S. 410, suggerieren, daß Melsheimer und Benjamin persönlich zur Führung des Prozesses ausgewählt wurden; nach der Entscheidung, den Prozeß dem Obersten Gericht zu übertragen, war dies aufgrund der gesetzlichen Vorschriften jedoch unabdingbar.

223 Notiz Langes für das Politbüro, zit. nach Klawitter, Rolle der ZKK, S. 54.

224 Vgl. für Thüringen Weber, Justiz und Diktatur, S. 173-209, 220-234; für Brandenburg Pohl, Justiz in Brandenburg (Manuskript), S. 187-189.

${ }_{225}$ Rundverfügung Nr. 11/51 der brandenburgischen Hauptabteilung Justiz, 16.1. 1951, in: Unrecht als System I, S. 78.

226 ZKK-Bericht über die Verhältnisse in der Justiz der DDR, mit Begleitschreiben von Lange an Ulbricht, 27.6. 1951, BAB, DC1 Nr. 5248. Eine ausführlichere Auseinandersetzung damit erfolgt in Kap. B.IX.1. 
schaftsstrafsachen ${ }^{227}$, die von Benjamin 1948 befürchtete Entwicklung der Justizbehörden zu "Jasagern“ der ZKK abgeschlossen.

Das Jahr 1948 markiert auch in der Justizsteuerung, wie sie von der DJV und später vom MdJ vorgenommen wurde, eine Zäsur. Erst infolge der Justizkonferenz vom November 1948 ging man seit 1949 in der Zentralverwaltung ernsthaft daran, die Voraussetzungen für eine systematische Lenkung der Rechtsprechung von Berlin aus zu schaffen. Die Schwerpunkte, die bei der politischen und der Wirtschaftsstrafjustiz zu liegen hatten, sowie die Ausrichtung auf harte Bestrafungen gab die SMAD-Rechtsabteilung vor. Dabei griff die DJV weitgehend auf Überwachungs- und Kontrollmechanismen zurück, die sie bereits in den Jahren zuvor zur Erfüllung ihrer Berichts- und Kontrollaufgaben im Dienste der Militärverwaltung entwickelt hatte. Nun wurden Berichterstattung, Revisionen und Rundverfügungen freilich in zunehmendem Maße eingesetzt, um die Rechtsprechung im Sinne einer größtmöglichen Homogenität und einer weitgehenden Anpassung an die Politik zu steuern. Effizienz und Effektivität der Justizsteuerung ließen jedoch noch stark zu wünschen übrig, da die Transformation des Justizwesens zu einem zentralisierten und politisierten System noch nicht weit genug fortgeschritten war.

Eine begrenzte Wirkung konnte mit den Vorgaben des MdJ nur punktuell und unter Aufbietung massiver Kräfte erreicht werden, wie etwa bei der Justizkampagne gegen die Buntmetalldiebstähle. Die Initiative zu solchen Kampagnen ging jedoch nie vom $\mathrm{MdJ}$, sondern stets von anderen Instanzen, etwa von sowjetischen Dienststellen oder vom MfS aus ${ }^{228}$, was die Frage nach der Bedeutung des MdJ in der Justizsteuerung insgesamt aufwirft. Zwischen 1949 und 1951 besaß es formell aufgrund seines Anweisungsrechts gegenüber den Justizjuristen eine größere Bedeutung als das Oberste Gericht und die Oberste Staatsanwaltschaft. Mit der Verselbständigung und Zentralisierung der Staatsanwaltschaft verlor das Justizministerium den direkten Zugang zu den Staatsanwälten; gegen alle Versuche des Obersten Gerichts, mit den Gerichten unmittelbaren Kontakt zu erhalten, setzte sich Fechner bis 1953 jedoch hartnäckig und erfolgreich zur Wehr. Die zunehmende Ausschaltung des Ministeriums aus der Justizsteuerung war jedoch nicht zu verhindern, da mächtigere Instanzen sich hier hineindrängten. Bei Bedarf war es die SED-Führung selbst, die den Ausgang politischer Verfahren unter Umgehung des MdJ bestimmte und dabei nicht vor einer massiven Verletzung rechtsstaatlicher Prinzipien zurückscheute: Die Waldheimer Prozesse sind hier das herausragende Beispiel. Aufgrund des Mißtrauens der SED gegenüber dem noch nicht völlig von „reaktionären“ Persönlichkeiten gesäuberten Rechtsstab wurden jedoch auch anderen Einrichtungen, denen die Einhaltung der politischen Linie eher zugetraut wurde, maßgebliche Einflußmöglichkeiten auf die politische und

227 Das Ende der Betätigung der ZKK als Ermittlungsorgan in Wirtschaftsstrafsachen hatte mehrere Ursachen: Erstens bedeutete das Staatsanwaltschaftsgesetz vom Mai 1952 einen Kompetenzverlust für die ZKK; zweitens trat das MfS ab 1952 als Untersuchungsorgan zusehends an ihre Stelle; drittens war 1952/53 die erste Phase der Enteignungen auf "kaltem Wege“ weitgehend abgeschlossen. Vgl. Weber, Justiz und Diktatur, S. 291, 248, und Statut der Zentralen Kommission für Staatliche Kontrolle und ihrer Organe, 30. 4. 1953, in: GBl. 1953, S. 685-689.

228 Auch Weber, Justiz und Diktatur, S. 194, konstatiert, daß das MdJ erst dann zu radikalen Maßnahmen griff, wenn es dazu gedrängt wurde. 
die Wirtschaftsstrafjustiz eingeräumt. Am einflußreichsten dabei waren das MfS und die ZKK; aber auch die Wirtschaftsverwaltungen und das Amt für Kontrolle des Warenverkehrs erhielten aufgrund der Wirtschaftsstrafverordnung bzw. des Handelsschutzgesetzes Befugnisse, die eigentlich den Justizorganen zustanden. Nur bei den Verfahren aufgrund des Handelsschutzgesetzes gelang es - vor dem Hintergrund sowjetischer Weisungen - die außerjustitielle Instanz wieder zurückzudrängen; das verlorengegangene Terrain wurde freilich nicht vom MdJ, sondern von der Staatsanwaltschaft zurückgewonnen. Schließlich hatten die politischen und Wirtschaftsstrafverfahren, in denen MfS und ZKK als Untersuchungsorgane fungierten, auch Rückwirkungen auf das Justizwesen: Denn mit der Einrichtung von Sonderstrafkammern in beiden Fällen wurde der auch in die DDR-Verfassung aufgenommene rechtsstaatliche Grundsatz, keine Sondergerichte zu errichten, elementar verletzt. 